\title{
SEARCH ACTIVITY CONCEPT: RELATIONSHIP BETWEEN BEHAVIOR, HEALTH AND BRAIN FUNCTIONS
}

\author{
Vadim S. Rotenberg \\ Tel-Aviv University, Sackler Medical School and Abarbanel Mental Health Center, Bat-Yam, Israel \\ Received March 2, 2009; accepted March 15, 2009
}

\begin{abstract}
Search activity concept provides a new classification of the behavior which distinguishes search activity (activity in the uncertain situation with the constant feedback between behavior and its outcome), stereotyped behavior with a definite probability forecast, panic (activity without feedback between activity and its outcome) and renunciation of search. Only search activity which includes fight, flight, orienting behavior and creativity raises the body's resistance to stress, to natural and experimentally induced pathology whereas renunciation of search which display itself in freezing, helplessness and depression forms a nonspecific predisposition to somatic disturbances (e.g. psychosomatic diseases). Dreams in REM sleep are regarded as a specific form of search activity aimed at compensating for the lack of search in waking. REM sleep deprivation on a small as well as on rotating platform raises the requirement in REM sleep by frustrating search activity. It is suggested that in wakefulness characterized by the prominent search activity the inhibitory alpha-2adrenoreceptors became less sensitive to stimulation and consequently in this state the activity of the brain monoamine neurons is less limited by the level of brain monoamines. During renunciation of search brain monoamine synthesis is not stimulated by monoamine exhaustion. In REM sleep the critical level of brain monoamines for search activity to start is lower than in wakefulness and alpha-2-adrenoreceptors are less sensitive than in the state of renunciation of search although more sensitive than during search behavior in waking. REM sleep indirectly contributes to memory consolidation by carrying out its main function - restoration of search activity. A functionally sufficient REM sleep contains search activity in dreams (subject is active in his/her own dream scenario) while in functionally insufficient REM sleep dreams are characterized by subject's passive position and feeling of helplessness. REM sleep insufficiency is an obligate condition for mental and somatic disorders to appear. The difference between normal (adaptive) and pathological (maladaptive) emotional tension is determined by the presence or absence of search activity in the structure of emotional tension. Repression of the unacceptable motive causing neurotic anxiety is a human variant of renunciation of search. Hypochondriac symptoms are in negative relationships with psychosomatic disorders and they, as well as positive symptoms in schizophrenia and anorectic behavior in anorexia nervosa, represent a pathological misdirected search activity.
\end{abstract}

Key words: Anorexia; Anxiety; Brain Monoamines; Neurosis; Psychosomatic Diseases; Schizophrenia; Search Activity; REM Sleep

\section{INTRODUCTION}

Stress theory of Selye (1974) integrated data of physiological and clinical investigations related to the level of subject's health in front of life challenges. According to this theory, an intensive and/or long lasting stress (distress) is considered to be one of the main factors predisposing subject to mental and psychosomatic disorders. This theory was confirmed in many investigations on animals and supported by numerous clinical cases.
However, this theory contains some serious contradictions and fails to explain a substantial part of clinical data. Thus, there are no relevant methods and even no theoretical approaches for the preliminary distinction of stress with positive outcome (eustress) from stress with negative outcome (distress). It is difficult to explain why different stressors cause initially the increase of body resistance (in comparison to the neutral state without stress) while being continued in the same frame they are almost inevitably leading to the tremendous de-

\footnotetext{
Correspondence to: Vadim Rotenberg, MD,

e-mail:vadir@post.tau.ac.il
} 
crease of body resistance (stage of exhaustion). Actually, it is hard to imagine how the same condition without any qualitative alterations is changing subject's state to the opposite one.

It is worth to emphasize that psychosomatic disorders may also appear when stressful situation has a successful outcome accompanied by positive emotional state ("diseases of achievement"). Such diseases appear not during the fight by itself, no matter for how long this fight is going on, but only after a desired goal is already achieved.

This phenomenon is difficult to explain using the concept of exhaustion because a new goal or the unexpected prolongation of stress usually prevents psychosomatic disorders.

On the other hand, even a very long and intensive stress may increase body resistance instead of decreasing it. For example during the Second World War participants in military operations or individuals who did hard work in the rear showed a drop in the rate of diseases compared to the pre-war period (Natelson, 1983). Furthermore, while many concentration camp prisoners have died due to the development of psychosomatic disorders, those prisoners who survived until their release often exhibited the disappearance of the symptoms of their pre-camp psychosomatic diseases, and these diseases in some of them come back soon after the release. However, if the same stress may cause either exacerbation or disappearance of the diseases it means that it is necessary to search for additional factors explaining the difference in stress outcome.

According to some authors (Laudenslager et al., 1983; De Boer et al., 1990; Rodin, 1986; Mason et al., 1990; Levine \& Ursin, 1991) a controllability and loss of control are crucial factors determining stress outcome. Real or perceived control prevents somatic disorders in stressful conditions while loss of control predisposes subject to these disorders. Nevertheless, it was shown in some investigations performed in animals (Seligman 1982) and in humans (Brosschot et al., 1992) that strong efforts, even being unsuccessful and being performed by subjects without any illusions according to their controllability might increase body resistance and immune activity. However, in other investigations unsuccessful efforts are often leading to learned helplessness (Seligman, 1975) accompanied by somatic disorders.

The concept of coping as a mediator of stress outcome is central in the modern stress theory. According to this concept, subject's overt and covert behavior in front of stressful life events determines the stress outcome in the domain of the psychological and somatic health. However, different authors proposed different lists of coping mechanisms (see Folkman \& Lazarus, 1988) and it is still unknown whether some of them have definite advantages in comparison to others, and whether they are qualitatively different.
The goal of this paper is to propose a special psychobehavioral mechanism crucial for health protection vs. health disturbance in stressful and non-stressful conditions and to discuss the application of this mechanism to physiology, psychology and medicine.

\section{SEARCH ACTIVITY CONCEPT: AN EXPERI- MENTAL BACKGROUND}

Search activity concept arose from an analysis of the results of our own investigations and their comparison with literary data in different fields. Basic experimental investigations have been performed in collaboration with V.V. Arshavsky. In the 1974-1978 period we have studied the influence of different types of behavior and emotional states on the course of experimental pathologic processes and sleep (Arshavsky \& Rotenberg, 1976; Rotenberg \& Arshavsky, 1979b). The subjects were rats and rabbits with lacquer-insulated bipolar nichrome electrodes 100 microns in diameter (the interelectrode distance was 0.8 millimeter) implanted in the lateral and ventromedial parts of the hypothalamus. Three or four days after the operation we tested the reaction that follows stimulation of the hypothalamic structures by one-second square pulse bursts each lasting a millisecond. They had a frequency of $60-80 \mathrm{~Hz}$ and an amplitude (with minimal current) of 100-180 microampers (microA) in the case of the reaction of self-stimulation and 40-80 microA in that of the reaction of avoidance. The experiments were conducted under conditions of free behavior. Stimulation of the lateral hypothalamus in rats, as a rule, provoked the beginning of self-stimulation with a frequency of 40 to 80 pedal pushes a minute. Stimulation of the ventromedial hypothalamus in both rats and rabbits evoked two types of behavior: 1) active defense reaction of the fight-flight type: flight, fury, jumps, nibbling at various objects to be found in the chamber, and 2) passive fear of the freezing type: the animals hid in one of the corners of the cage without trying to get out of it, pressed themselves to the floor and froze with tensed muscles, exhibited frequent piloerection and dyspnea, constant defecation and urination. Freezing behavior was often although not always accompanied by an increase in heart rate and arterial pressure. The thresholds of electric stimulation for elucidation freezing were, as a rule, higher than those exhibited in the case of active-defense behavior.

In order to check the effect of the different emotional states and different types of behavior on the body resistance to somatic disorders, we have studied the dynamics of different forms of experimentally induced pathology. We have used the following models: anaphylactoid edema in the case of the intra-abdominal injection of 1.5 milliliters of protein of a hen egg; arrythmia of cardiac 


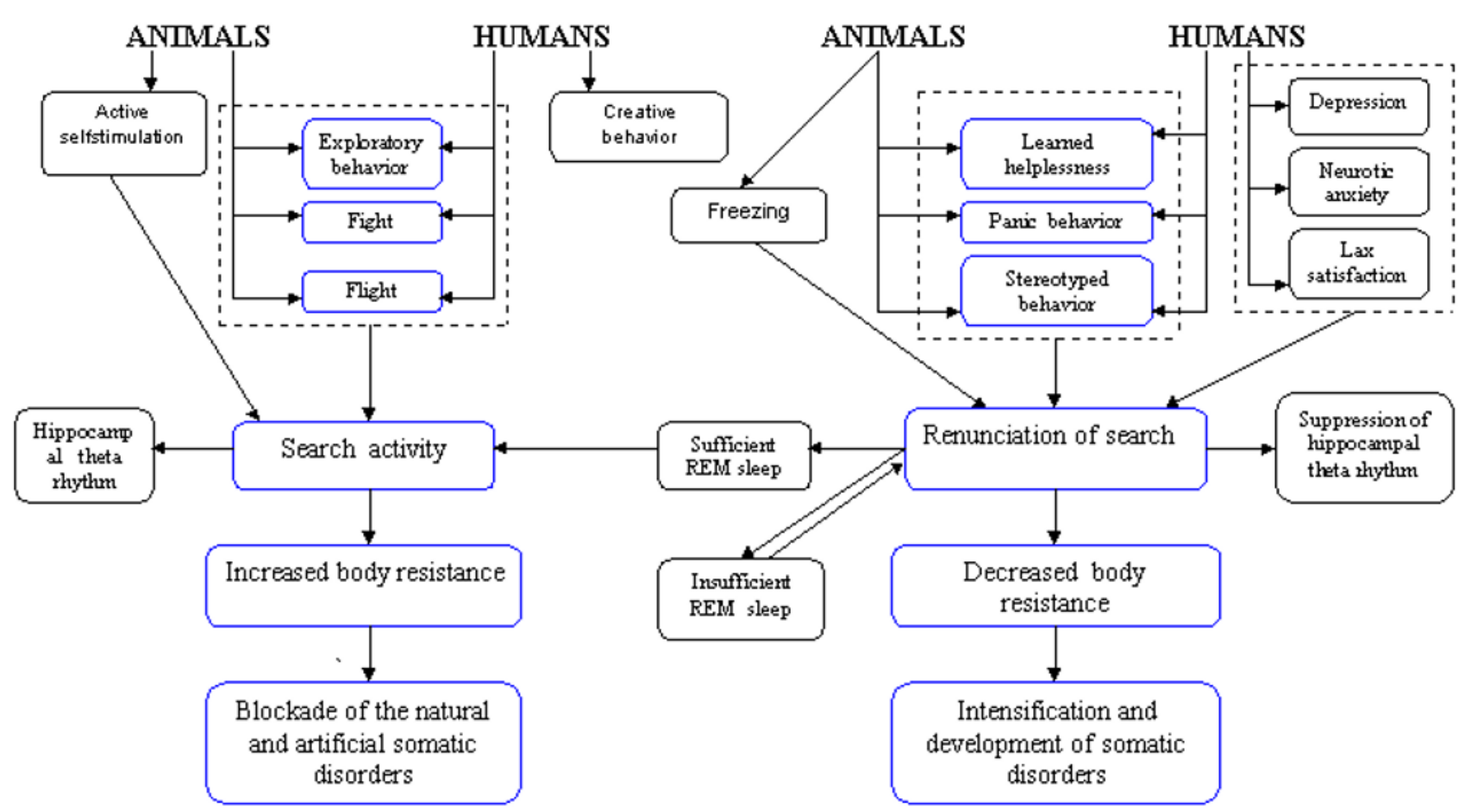

Figure 1. Relationships between behavior, body resistance and REM sleep functions.

contractions in the case of a parenteral injection of sublethal doses of aconitine; epileptic focus (application through a chronically implanted cannula of some metal cobalt powder to the sensori-motor region of the cortex); extrapyramidal disturbances (rise of muscular tension, constraint, tremor with a frequency of $3-4 \mathrm{hz}$ and an amplitude of 5-10 angular degrees) with intramuscular injection of neuroleptics (aminazine, 2 milligrams per kilogram); "proclivity" to the use of alcohol.

The dynamics of these forms of artificial pathology were studied in control animals, which were not exposed either to self-stimulation or to stimulation of hypothalamic structures. In the experimental animals 10 to 15 minutes of stimulation of these structures induced the aforementioned types of behavior. Through the implanted electrodes an electroencephalograph registered the biopotentials of the hypothalamic structures and hippocampus. The experiments were followed by the examination of the electrode localization on the brain's serial sections.

The basic findings can be summed up as follows. Both active self-stimulation and active defense behavior of the fight-flight type reduced the distinction of pathologic manifestations or even completely prevented their emergence. Passive self-stimulation of the lateral hypothalamus (when a rat simply lay down on the pedal thus closing the circuit and sending rare pulse bursts to the brain) did not influence the course of the pathologic process. In contrast, freezing predictably speeds the progress of the pathologic process, rendering its course more difficult. For example, the duration of epileptic seizures (cobalt epilepsy) in the "mirror" focus equaled $1.3 \pm 0.08$ seconds in the control series, $0.98 \pm 0.08$ seconds in that of active preliminary self-stimulation, $0.96 \pm 0.08$ seconds in that of active defense behavior and $2.4 \pm 0.3$ seconds in that of passive behavior of the freezing type $(p<0.05)$. The manifestation of anaphylactoid edema was measured by the change in the shadow's width on a contact print. In control the edema equaled $3.25 \pm 0.16$ millimeters, after self-stimulation it was weakly expressed $(1.04 \pm 0.12$ millimeters $)$, freezing made the latent period of edema emergence almost twice as short and edema by itself was equal to that observed in control animals. At the same time, active defense reaction reduced the degree of edema $(2.2 \pm 0.1$ millimeter) in comparison to the control state and freezing. The injections of librium changed the character of animal's self-stimulation; animal was not "playing" with the pedal but instead lay down on the pedal and closed the circuit sending pulse bursts to the positive rewarding brain structures. In this case the development of edema was not blocked and it equaled $3.27 \pm 0.21$ millimeters. Other experimental models, including model of artificial myocardiac infarction (Simonov, 1981) gave similar results.

The main question raised by these data was the following: what is the common basis of the protective effect of active self-stimulation and active-defense behavior? What brings together these two behavioral forms mak- 
ing them opposite to freezing and passive selfstimulation? We have performed a substantial analysis of this topic (Rotenberg, 1984)

Apparently, neither the positive nor the negative sign of the dominant emotion is crucial: in the case of selfstimulation, behavior is determined by positive reinforcement whereas the reaction of the fight-flight type, as well as freezing, signifies the domination of negative emotions. At the same time, passive self-stimulation exercises an effect similar to that of freezing although these behavioral forms are accompanied by emotions of the opposite sign. The differentiation of behavioral types based on the "approach" and "avoidance" principle also fails to furnish the clue to the problem: freezing and flight are classed with avoidance behavior but exert the opposite influence on the body's resistance. At the same time, flight and self-stimulation according to this criterion are the opposite behavioral types but exercise a similar effect on the course of pathological processes. Apparently, the character of autonomic reactions is not basic to the problem either. It is true that in all types of behavior blocking the development of pathologic processes the activity of the sympathetic system is the dominant factor. However, in the case of the behavior furthering the development of pathological processes, sympathetic system is often also very active. In freezing, defecation and urination as signs of the parasympathetic activity were frequently accompanied by piloerection, mydriasis, tachycardia and high blood pressure (see also Anderson \& Jingling, 1978). Thus, the animal exhibits, as it were, the anxious expectation of catastrophe. Furthermore, it has been demonstrated (Valdman, Kozlovskaya, \& Medvedev, 1979) that whereas in the case of active defense avoidance the blood pressure rapidly normalizes after the completion of a stressful situation, in the case of freezing it persists for a prolonged period at a relatively high level.

Finally, it could be assumed that the basic factor influencing the course of experimental pathology is motor activity: whereas in self-stimulation and the fight-flight behavior it is at its peak, in freezing and in passive selfstimulation it is almost completely absent. However, many studies in the literature contradict this assumption. Thus, when animals were trained to inhibit motor activity arbitrarily in order to avoid electric shock (passive avoidance), the successful "learners" had less gastrointestinal lesions than those animals that failed to inhibit motor behavior (Goesling, Buchholz \& Carreira, 1974). On the other hand, when animal is exposed to unavoidable electric shock it cannot prevent by coping behavior, ulceration of the gastrointestinal tract correlates with the intensity of motor activity (Weiss, 1977). Weiss emphasizes the absence of cause-and-effect relationships in these investigations: it is not the motor that accounts for the exacerbation of the ulcerous process. However, both indices increase in parallel, indicating that motor activity does not prevent the development of somatic pathology. It is also known that a nonpurposeful motor activity, which predictably manifests itself at initial stages of the development of learned helplessness, does not prevent the development of this state, which is accompanied by disturbances of different somatic systems (Miller, Rosellini, \& Seligman, 1977). Apparently, it is not motor activity that forms the basic protective factor in cases of different behavior types.

What then is there in common between self-stimulation and the fight-flight behavior, and what criterion makes them opposite to freezing in our investigations? I assumed that this criterion is search activity (Figure 1).

By search activity is understood activity designed to change the situation or the subject's attitude to it in the absence of a definite forecast of the results of such activity, but with constant monitoring of the results at all stages of activity. Without an appropriate monitoring it would be impossible to change a direction of search in the case of its inefficiency. This definition makes it clear that certain behavioral categories cannot be classed with search behavior. This primarily applies to all forms of stereotyped behavior having a quite definite forecast of results. The role of activity in anticipating and confronting stressful situations was emphasized by Gal and Lazarus (1975) however they do not propose the notion of search activity and do not discriminate search activity from any other forms of subject's activity. On the other hand, panicky behavior at first glance may seem to imitate search behavior but differ from it by the disturbance of the feedback between the outcome of activity and its regulation. Really, during panic the results of the activity are not considered at any stage and cannot be used for the correction of behavior. No line of activity can be traced to its conclusion and panicky behavior easily becomes imitative, approaching stereotyped behavior. Finally, the antipode of search behavior is the state of renunciation of search, which in animals may assume the form of freezing. (Table 1) Learned helplessness in animals and humans as an outcome of regular failures (Seligman, 1975) is also a typical example of renunciation of search.

In the Introduction I have stressed that the controllability vs. loss of control are considered by some authors to be crucial for stress outcome. Loss of control or lack of the sense of control are the main notions of the learned helplessness theory (Peterson et al., 1993). By control is understood a relationship between action and outcome. An inescapably shocked rat can be immunized against helplessness if it was trained before to escape shock by using a particular behavior. Thus, according to Peterson at al., 1993, the previous experience of control eliminates the learned helplessness effect. However, is it really a sense of control that prevents learned helplessness? And is it really an absence of the sense of control determining the development of learned helplessness? 
Peterson et al., emphasized that learned helplessness is going to ensue even if the uncontrollable event is positive or neutral, but independent on the animal's behavior. According to these authors, animals exposed to positive events independently of their behavior should learn that these events are uncontrollable. Due to this uncontrollability, animals became vulnerable to the development of learned helplessness.

Table 1. Main differential features of different forms of behavior.

\begin{tabular}{|c|c|c|c|}
\hline $\begin{array}{c}\text { Active } \\
\text { behavior }\end{array}$ & $\begin{array}{c}\text { Unpredictable } \\
\text { outcome }\end{array}$ & $\begin{array}{c}\text { Analysis } \\
\text { of results } \\
\text { and } \\
\text { situation }\end{array}$ & \\
\hline+ & + & + & $\begin{array}{c}\text { Searh } \\
\text { activity }\end{array}$ \\
\hline+ & + & - & $\begin{array}{c}\text { Chaotic } \\
\text { behavior }\end{array}$ \\
\hline+ & - & + & $\begin{array}{c}\text { Stereotyped } \\
\text { behavior }\end{array}$ \\
\hline- & + & - & $\begin{array}{c}\text { Renounce } \\
\text { of search }\end{array}$ \\
\hline
\end{tabular}

However, if the outcome of any action and any response is positive, or if the outcome is positive even without any special response, from my point of view, animal receives a quite opposite experience - an experience of omnipotent control, because every action causes a positive outcome. If subject achieves goals in any case what can be a real basis for the subjective conclusion that control is absent? It is only the conclusion of the investigators. Although humans are more sophisticated than animals it is true also for humans, especially by taking into consideration the tendency of healthy subjects to create positive illusions (Taylor \& Brown, 1994) and to believe that they can control things more than is actually the case. When subjects are solving easy intellectual tasks and are successful in 100\% (Jones et al., 1977), it is very doubtful that they come to the conclusion that they are unable to control the situation. I suppose, in this condition they have a sense of a very high control. However, it does not immunize them to learned helplessness when they subsequently confront with regular failures. Quite opposite, they became more predisposed to learned helplessness in comparison to subjects who received difficult tasks and were able to solve only $50 \%$ of these tasks. According to the search activity concept, it happens because subjects achieved their $100 \%$ success without additional efforts, without search, on the basis of stereotyped behavior. This experiment shows that not the controllability by itself, but only efforts to achieve control (search activity) immunize subject to learned helplessness.
Perceived control may relate to two different conditions:

1. A definite forecast of the outcome of the objective situation. Such estimation of the situation usually causes stereotyped behavior. It can facilitate adaptation only in very particular (often artificial) conditions.

2. Subject feels himself to be able to control the situation without definite probability forecast of the outcome of the situation by itself. In this condition perceived control is actually a potential control and relates not to the situation but to the implicit evaluation of subject's ability to cope with the unpredictable situation. This ability is based on search activity.

I suppose that it is necessary to discriminate two forms of learned helplessness (LH) (Rotenberg, 1996). If animal learns that punishments (footshocks) are limited in time and space, a conditioned LH appears tied only to specific conditions. The animal remains active in all other situations (Abramson et al., 1978). Such restricted LH does not contribute to renunciation of search as a global state. The difference between conditioned and generalized LH may explain different outcomes of chronic stress (Yehuda et al., 1993 ). Chronic stress can cause the physiological exhaustion if combined with generalized helplessness (renunciation of search). Being combined with conditioned helplessness, stress causes attenuation of hormonal response however the latter can be displaced by the increased response in front of novel, acute stressor that stimulates search activity.

Search activity can be absent not only due to the renunciation of search in stressful conditions. It can be absent if subject is completely satisfied with the situation and if search, with its unpredictable outcome, is threatening. In cases such as these, appearing mostly in artificial conditions, the animal is motivated to give up search behavior. However, some of the specimens even in these cases, too, exhibit a tendency toward search behavior even if the latter involves risks and fear. When rats were placed in comfortable conditions, in which they had sex partners and a sufficient food, some of them shortly attempted to enter the unexplored neighboring premise although these attempts were accompanied by pronounced emotional tension. This manifested itself in an increased heart rate and in defecation (Simonov, 1975).

Thus, it would be incorrect to assume that search activity in all cases is merely a "servant" of some irrelevant requirements, although the latter happens very often. If the organism only follows the course of a continuously changing world with the aim to adapt to it, it may lose time and initiative. It cannot be excluded that, alongside certain biologic requirements, there is one in search, which is anti-homeostatic. Exploratory activity without any pragmatic necessity reflects a high level of search requirement, as does creativity in humans. 
Search behavior in animals is categorized as all types of active defense behavior (both aggression and active avoidance) as well as the active self-stimulation of the brain zones of positive reinforcement. Such selfstimulation is a complex multi-component behavior, which includes appetence, aversion, and search activity proper (Grastyan, 1976). It has been shown that selfstimulation is obtainable from the same brain structures whose forcible stimulation creates orienting-exploratory (search) behavior; the duration of self-stimulation correlates with the manifestation of the general exploratory reaction of the animal being stimulated (Schiff, Rusak and Block, 1971); self-stimulation is in competitive relations with stereotyped behavior (Wauquier, 1980). In many mammals (cats, rats etc.) the electrophysiological correlate of search behavior is synchronous highamplitude theta-rhythm in the hippocampus. None of the existing hypotheses pertaining to the functional relevance of this rhythm contradicts the above mentioned assumption: search activity plays a great role in learning, in directed attention, in behavior planning, in the organization of arbitrary motor acts, and in the selective memorizing of information (Rotenberg, 1984). At the same time, stereotyped behavior with the definite forecast of the results of actions which promotes satisfaction of requirements ( for instance, during consummatory behavior) is unaccompanied by hippocampal thetarhythm (Kramis and Routtenberg, 1977).

The brain system related to search activity (to orienting response, novelty detection etc.) is a widely distributed network involving hippocampus, cingulate and limbic areas, and prefrontal and posterior association cortex (Knight, 1996). It was shown recently (Procyk et al., 2000) that it is a group of anterior cingulate neurons being more active during search behavior, whereas another group is more active during the routine behavior. Search related neuron activities are specific to a situation requiring flexibility of behavioral responses and evaluation of the outcomes.

The identification of purely behavioral criteria of search presents certain difficulties. As we have already mentioned above, an identification of search behavior with motor behavior may lead to serious errors. Search can proceed without any manifestations in the motor sphere if the movements pose a threat or, according to the natural or experimental conditions, involve a punishment. The temporary inhibition of overt behavior at the encounter with a new, surprising, or emotionally significant situation is a very well tested phenomenon (Gray, 1982; Morrison, 1982). During such inhibition intense reappraisal of the situation proceeds; that is, search behavior. Passive avoidance works. It is not a renunciation of search. For example, in the Porsolt Test intense search activity characterizes the rats that find the shallowest place in the pool sooner than others, where they can maintain immobility resting on their tail. Converse- ly, less adapted rats inclined to panicky behavior spend a much longer time performing exhaustive movements around the pool (Hawkins et al., 1980). This unproductive chaotic behavior appears to be inversely correlated with search activity. An exclusive orientation to motor activity without consideration of the entire context of the situation and without registration of the activity of hippocampus frequently leads to the erroneous identification of such salutary passive avoidance with the reaction of surrender (renunciation of search) of the freezing type.

\section{SEARCH ACTIVITY IN HUMANS: ROLE OF AGE AND GENDER}

Tracing the boundaries of search activity in humans is a still more complex problem, where psychological processes unaccompanied by overt behavior play a still greater role. Among humans, search manifests itself in the planning, fantasizing, and rethinking of the situation. Search activity may display itself in the pathological, perversely oriented form (see paragraphs about schizophrenia, anorexia nervosa and neuroses). Few years ago we have developed a projective questionnaire measuring attitudes towards different types of behavior in indefinite situations - BASE Test (Venger, Rotenberg, \& Desyatnikov, 1996), however this test also does not cover all possible manifestations of search activity, for instance the creative behavior. Therefore, in humans, just as in animals, it is simpler to indicate states and forms of behavior that undoubtedly do not contain the search activity component. Renunciation of search in humans includes depression and the reaction of surrender, which Engel and Schmale (1967) have called give-up - giving-up complex and which predicts the development of psychosomatic disorders. Within the same category lies unproductive neurotic-like anxiety (see later).

The test BASE (Behavioral Attitudes and Search Evaluation) includes descriptions of 16 open situations with four possible reactions on each of them. The tested subject has to choose two reactions on each situation: the most appropriate from his/her point of view and the least appropriate. The test BASE provides an opportunity for quantitative measurement of each of above mentioned behavioral attitudes: 1) search activity; 2) stereotyped behavior; 3) chaotic (panicky) behavior; 4) renunciation of search (passive behavior). The test situations are indefinite enough, so no one of the four reactions is more advantageous than others, i.e., all of them look equally acceptable both ethically and pragmatically.

We have investigated 201 Russian-speaking adults and 143 adolescents from the families of the new immigrants in Israel. The relationships between behavioral attitudes and distress level have been analyzed separately for both genders and for younger (10-12 years old) 
and older (13-15 years old) adolescents. (Rotenberg, Kutsay, \& Venger, 1998; 2001).

We have found that in healthy adult subjects search activity is significantly higher in men than in women; in men attitude toward search activity is almost twice higher than attitude toward stereotyped behavior, while in women they are almost equal. At the same time, passive behavior in women is slightly but significantly higher than in men, and as soon as the life condition became less stressful, stereotyped activity dominates. In men search activity is more flexible than in women, and in stressful conditions, when stress of emigration is still in process search activity has a tendency to increase. The limitation of the present investigation is determined by the selection of the special group of subjects characterized by the moderate economical status and by similar (high) attitudes towards education of their children. If difference between genders in behavioral attitudes will be confirmed in further investigations, it would mean that it is necessary to suggest different norms for men and women according to the behavioral attitudes.

The relatively lower level of search activity in women may explain the prevalence of demoralization in women in comparison to men (Dohrenwend et al., 1980). At the same time, the level of mortality in general is higher in men and this data seems to be opposite to the main statements of the search activity concept. However, it is possible to propose few speculative explanations of this contradiction: 1. The higher level of mortality is partly related to the higher level of risky behavior in men (different accidents, alcohol and drug addiction etc.). Such forms of deviant behavior often reflect increased sensation seeking (Zuckerman, 1984), the latter representing a particular and destructive form of search activity. 2 . The higher is the initial level of search activity the more dangerous for health and damaging is an abrupt renunciation of search (giving up) caused by stressful conditions and obstacles. For instance, men often belong to the so-called type A, and persons of this type of behavior, being initially high active and achievement oriented, are at the same time less resistant to stable failures and unavoidable obstacles in comparison to more relaxed type B (see chapter on psychosomatic disorders of the present paper). 3.Men more often than women display a tendency to repress negative sensory information from the body (according to the "masculine" type of character) and thus are more predisposed to the catastrophic exacerbation of somatic disorders (sudden myocardial infarction etc.).

In adolescents the tendency to search activity increases with age, while tendency to the chaotic behavior decreases, especially in boys. Girls were less disposed than boys to chaotic behavior and more disposed to passivity, especially in the younger group. Girls of the older group were less than boys disposed to search activity. The general level of distress in adolescents increases from age $10-12$ to age 13-15. However, inside both groups, and especially inside the older group, the lower level of distress corresponds to the higher level of search activity. In the younger group also a tendency to stereotyped behavior was higher when the level of distress and demoralization was low. In the older group only the tendency to search behavior is higher in both genders when the level of distress is low. However, in girls stereotyped behavior is also relatively protective.

Thus, men in any age are more predisposed to search activity in the uncertain situation, while women are more predisposed to stereotyped behavior, especially being out of stressful conditions. In stressful conditions search activity is the most adaptive form of behavior. We have compared two groups of 15-18 year old adolescents, new emigrants in Israel (Venger et al., 1996). Emigration is a typical stress. The first group consisted of 60 subjects whose social adjustment was satisfactory: they had high academic achievements and were motivated to continue their education. The second group included 57 subjects whose social adjustment was problematic: they neither worked nor attended school regularly, and had no concrete plans for future. Attitude towards search activity was much less and attitude towards renunciation of search was higher in the second group.

It is necessary to take into consideration that test BASE estimates attitudes towards different types of behavior however these attitudes may be realize in the overt behavior or not, and it depends on the real circumstances and on some other psychological variables. In some objective conditions even high attitudes towards search activity may be frustrated.

The resistance to the development of renunciation of search in stressful conditions is related to some psychological features, in particular to the reaction to frustration according to Rosenzweig, 1935 ( Rotenberg \& Korosteleva, 1990). A high fixation on the obstacle predisposes subject to renunciation of search while fixation on the overcoming of the obstacle protects subject from this behavior.

\section{SEARCH ACTIVITY IN THE CONTEXT OF DIF- FERENT PSYCHOLOGICAL CONCEPTS}

In humans positive feedback exists between search activity and self-esteem (Rotenberg et al., 1996). Search activity requires hard efforts in indefinite situation and is often accompanied by failures. High self-esteem increases the subject's resistance to obstacles and failures that might otherwise trigger surrender reaction in an individual who doubts his own abilities (Romney, 1993). On the other hand, the greater the search activity, the more the person feels able to cope with obstacles. He feels himself a subject who does not give up, and this has a positive influence on self-evaluation. Subjects with low self-esteem give up (renounce search activity) 
when informed of failure (Forsman \& Johnson, 1993). Those who give up when confronted with a stressful situation express readiness to blame themselves for the frustrating situation (Rotenberg \& Korosteleva, 1990). They do not attempt to identify objective causes for the failure and to learn from the experience.

It was shown that persons with high but unstable selfesteem are using from time to time the so-called selfhandicapping strategy (creation of artificial obstacles on the way to achievements) in order to increase and stabilize their self-esteem (Tice, 1991; Newman \& Wadas, 1997). In order to overcome these additional obstacles, subject has to mobilize his/her skills and search activity, and it may be an important part of the self-esteem enhancement.

Despite the close interrelationship between search activity and self-esteem, search activity is not merely a behavioral manifestation of high self-esteem. In some situations self-esteem can be high, while search activity nevertheless decreases. For instance, search activity often tends to diminish immediately following achievements of a personally rewarding goal if it is the most desirable, "final" goal (Rotenberg \& Arshavsky, 1984). Yet, the subject's self-concept in this condition might be high.

Alternatively, search activity can begin in some situations while self-esteem is low. It is well known that depressed patients can suddenly become active in response to a catastrophic or life threatening event. However, if the required activity is sustained over a period of time, an increase of self-esteem may result, ultimately leading to a decrease in depression.

The concept of optimism is also a concept strong related to the search activity concept (Scheier et al., 1994; Peterson, 2000). It was shown that dispositional optimism is beneficial for physical and psychological well-being. Optimistic men undergoing coronary artery bypass surgery evidenced a more rapid physical recovery, and there are many similar facts. The differences in outcome between optimists and pessimists derive partly from differences in the manner in which they cope with life challenges. Optimists tend to use more problem-focused coping strategies than do pessimists. When such strategy is not available, optimists turn to other adaptive coping strategies such as acceptance, positive reconsideration of situation and sense of humor. Pessimists tend to cope through overt denial and by mentally and behaviorally disengaging from the goals with which stressor is interfering, regardless of whether something can be done to solve the problem or not. Thus, speaking in our terms, optimists are more predisposed to search activity and pessimists - to giving up, according to different expectancies for their future.

However, optimism-pessimism opposition is unable to explain many facts explained by the search activity concept. Positive vs. negative expectancies cannot explain diseases of achievements, when search activity suddenly drops. Positive expectancies and the advantage of optimism cannot explain the remission of depression after sudden negative events requiring subject to perform unavoidable efforts. It cannot explain the disappearance of psychosomatic disorders during the war or in concentration camps, I mean, its disappearance in subjects with the same personality structures that does not protect them from the diseases before stressful events. Finally, it cannot explain a negative outcome of surgery stress after relaxation training (see further).

Hope is another concept worth to discuss in the context of search activity concept. According to the notion (Snyder, 1994), hope $=$ mental willpower + waypower for goals. Hope is a cognitive set constantly involving what we think about ourselves in relation to our goals. Although hope includes a combination of outcome and efficacy expectancies, it is not a behavior with a feedback between activity and its outcome. Hope is always a goal-oriented and goal-dependent mental phenomenon, while search activity might be, in addition, a selfdetermined process, and for search activity and its impact on the health, process is more important than the pragmatic goal and pragmatic result. Hope is often a very important predisposition to search activity. However, it does not determine search activity. Subject can try to achieve goals behaving in a stereotyped way. Moreover, although hope is very important for stimulating and maintaining search activity, subject can continue this activity even without hope of the positive outcome ("stoicism"). In such situation the process by itself, the ability not to give up has a high value for the subject. Of course, it is possible to speculate that in this situation search activity by itself became a goal.

Few years after we have proposed the search activity concept, Cloninger (1986, 1987) presented a threedimensional theory of personality. This three underlying genetic dimensions of personality are novelty seeking, harm avoidance and reward dependence. Novelty seeking includes in this theory the same types of behavior we have ascribed to search activity: exploratory pursuit, appetitive approach and active avoidance of monotony and potential punishment. No doubts, novelty seeking is a clear example of search activity, and their brain monoamines mechanisms are similar, however the notion of novelty seeking does not cover the all domain. For instance, while active avoidance of monotony and exploratory pursuit really represent novelty seeking, it is doubtful whether the active avoidance of punishment belongs to the same category. It seems to be an overgeneralization of the term "novelty seeking", and the notion of "search activity" seems to be more appropriate for all these different forms of behavior.

The main differences between the three-dimensional concept of personality and search activity concept are the following: 
Novelty seeking concept does not discuss feedback between activity and its outcome, while it is a crucial point of the search activity concept.

Search activity is a psychobiological concept relevant for both human and animals, while Cloninger is discussing only personality dimensions.

Search activity concept relates behavior to body resistance and emphasizes the importance of the process of search for survival. Cloninger does not discuss this topic.

The opposite pole of search activity is renunciation of search which is in any case maladaptive, while low level of novelty seeking is adaptive for special conditions and characterizes well organized analytic decision makers. Such analytic activity often also requires search.

Harm avoidance does not discriminate clearly the adaptive passive avoidance and renunciation of search. Although severe harm avoidance, according to the symptoms, seems to correspond to renunciation of search, in Cloninger's theory it is not opposite to novelty seeking, which represents search activity.

\section{PHILOSOPHICAL BACKGROUND OF THE CONCEPT (and some clinical applications)}

What is the philosophical explanation of the relationships between behavioral attitudes and body resistance? I suggest that search activity protects health because without search activity (activity in the indefinite situation) individual and social progress would cease, adaptability in higher animals and creativity in humans will disappear and a general state of stagnation will appear. At the same time, search activity itself requires a lot of efforts and energy and stimulates the subject to enter stressful, potentially exhaustive conditions and situations. If search activity would not protect the subject's health in such situations, the most creative and active members of the population would become exhausted and ill. Search activity and body resistance, then, create a natural positive feedback, supporting progress, development, and evolution.

According to the search activity concept, the process of search is more important than its pragmatic outcome, which is the benefit of successful search behavior. The outcome can be negative, subject can fail in his efforts to overcome obstacles nevertheless until search activity is still present it protects health. Seligman (1982) confirmed in experiments that if an animal remains active in the case of inescapable stressors, its immune resistance is higher than in the case of passive behavior, even in an objectively controlled situation. Herein lies the basic difference between the conception of search activity and the conception of coping behavior: coping must be successful to be meaningful. Another difference is the inclusion in search behavior of a wider scope of phenomena than is usually understood by coping behavior: in particular, spontaneous creative activity and orientation-exploratory behavior, which are not related to stress. Coping as a concept implies conditions of stress and challenge and cannot explain, for instance, the nature of the "diseases of achievements" which developed when stress is finished and challenge is no more relevant. According to the search activity concept, it is a prominent drop of search activity after achievement that is a real cause of such diseases.

If search activity during stress is more important for body resistance than the pragmatic outcome of stressful situation, it is possible to explain some contradictions in classical stress theory we have mentioned above. Stage of high resistance is displaced by the stage of exhaustion only if it is an alteration of subject's behavior from search activity to the renunciation of search. Long lasting stress like stress of the concentration camps may increase or decrease body resistance according to the dominating behavior.

In this context it is reasonable to mention some recent investigations on the topic of the long-lasting consequences of the Holocaust experience. Barak et al. (2005) have shown that aging Holocaust survivors are at increased risk of attempting suicide in comparison to people of the same age however without this experience, and these suicide attempts have been performed around fifty-sixty years after the traumatic experience. Barak et al. decided that these attempts reflects the reactivation of traumatic syndrome these survivors got dozens years before. According to Barak et al., aging made these people especially sensitive to this previous trauma and it was something like a repeated actualization of this traumatic experience, a second part of the post-traumatic syndrome. However, by taking into consideration that many of these Holocaust survivors have spent their life after the release in a quite active way and achieved many goals before being retired, makes this explanation very doubtful. From my point of view, it can be a more reasonable explanation. These people have survived during Holocaust due to very strong search activity, every- day fight for survival (many clinical cases confirm this proposition). In the post-war life they usually continued to display search activity and achieved many goals. The retirement and aging abruptly decreased their activity, and when search activity being initially very high became abruptly decreased it could cause more negative consequences for psychic health (like it happens in "diseases of achievement" when search activity suddenly stops). This hypothesis is indirectly confirmed by the investigation (Clarke et al., 2006) showing that the history of suicide attempts was highest in particularly those Holocaust survivors who were part of the resistant forces. My explanation means that it is possible to prevent the suicide attempts of these people by helping them to find goals and objects for search activity and self-realization relevant to their age, 
skills and opportunities, instead of trying to prevent the mythical "reactivation" of posttraumatic syndrome.

The objective control of situation based on stereotyped manipulations is less protective than continuous search activity without control. However, very often subjects are more able to continue search activity if they believe that they can control the situation, does not matter whether this feeling is erroneous or not. It has been shown that low self-esteem (caused by the inability to control a situation and by previous negative experience) and negative expectations regarding the outcome of efforts are factors that determine the renunciation of search (Rotenberg \& Korosteleva, 1990).

Preoperative relaxation training, instead of reducing stressfulness at surgery and improving recovery, had in some cases a tendency to increase stressfulness and impair recovery causing impaired immune functions (Manyande et al., 1992). According to the search activity concept, it can happen if the emotional tension reduced by the relaxation training contains search activity (Rotenberg et al., 1996). This proposition corresponds with data (Salmon, Pearce, \& Smith, 1992) that the preoperative state and trait anxiety correlated with the lower postoperative distress (according to the level of adrenaline and cortisol).

\section{ONTO-PHILOGENETIC ASPECTS}

If search activity is of such great biological relevance and renunciation of search leads to illness and death, why has the latter regressive behavior survived in the course of evolution and what makes it emerge?

All higher mammals including humans, at the early stages of ontogenesis inevitably experience helplessness determined by the relatively slow development of the central nervous system and all mechanisms (nervous, hormonal, and vegetative) that ensure subsequent search behavior. Naturally, during the early stages of ontogenesis such a state cannot be called renunciation of search. It is just nothing to be renounced. Passivity is normal and inevitable and the only available form of defense reaction for an immature organism. However, the organism thus acquires an early experience of passive reaction, an experience of helplessness. Both this experience and the ways to overcome it are of a very high relevance to the individual's entire subsequent life. In the case of a correct attitude of the primary group, above all the mother, child can successfully and painlessly overcome this early experience of helplessness. The child, gradually feeling constant support will pass on to increasingly active behavior. The child's first steps toward the development of search activity must proceed under the constant protection of the mother who helps the child to overcome fear of new situations, fear that consolidates the experience of passive reaction. All injuries in early childhood, from the physical separation from the mother to insufficient emotional contact with her and the feeling of insufficient protection due to strained relations between the parents can consolidate the experience of primary helplessness.

It was shown recently that maternal care in early childhood determines normal hippocampal synaptogenesis and cognitive development that display itself particularly in increased searching (Liu et al., 2000).

The lack of the maternal care in childhood and imprinting of early helplessness may lead to the development of a state of renunciation of search in an adult, especially if the emotional problems encountered in some way resemble conflicts of early childhood. Thus readiness for the development of neuroses and psychosomatic illnesses is formed. It is exactly from these general biological positions, the relations between early helplessness and the formation of search activity that the author proposes considering the Freudian theory of the role of early psycho-traumatic situations in the entire subsequent development of the individual. Regressive behavior in the cases of neuroses and psychosomatic illnesses according to Freud is indeed a regression towards a biologically earlier state of passiveness and helplessness that assumes the form of renunciation of search.

However, as the physiological mechanisms of search behavior mature, the child should gain increasing independence and be induced to overcome obstacles. The very fact of such ability to overcome, of the broadening of possibilities, exercises a powerful reinforcing effect, developing a search requirement in the childhood.

If an independent requirement for search activity is not shaped, in time throughout later life search behavior may emerge only as a forced reaction to complex situations, will be colored by negative emotions, and may fairly easily yield to the state of renunciation of search. At the early stage of development two opposite conditions may equally suppress the development in search requirement, constant (invariable) negative reinforcement and invariable positive outcome of any attempts. In the former case any activity, above all search activity, is depreciated in the subject's eyes and perceived as senseless and leading to punishment. The child soon learns that search is dangerous. In adult state, subject avoids any uncertain conditions requiring efforts and initiative. In the latter case, when all desires are satisfied immediately and without sufficient efforts, the search activity requirement is not formed because it is superfluous. If the search requirement is not sufficiently developed then subsequently at maturity even moderate stressful situations and moderate obstacles to the achievement of an aim may cause reaction of surrender (Rotenberg \& Arshavsky, 1984).

However, a search requirement does not guarantee the stable preservation of search activity either. Even when this requirement is pronounced, renunciation may occur if failures come in close succession and acquire greater 
relevance than the aims the subject strives to achieve and are greater than the positive reinforcement from search itself (Korosteleva \& Rotenberg, 1990). On the other hand, the more pronounced the search requirement and the higher the search activity, the more difficult it is to suppress it and to evolve learned helplessness. Search itself, irrespective of its final results, can come to represent an independent value and bring pleasure, as in the case of creativity. It can be assumed that in the animals and humans in which learned helplessness can never be evolved (Seligman, 1975) early experience has ensured a high level of search activity.

When the search requirement is not high, the cessation of search activity is not perceived subjectively as a stress creator. Furthermore, such cessation may be accompanied by a feeling of relief or relaxation. However, the body's resistance to various harmful factors then decreases and the organism becomes more vulnerable like in the surgery stress after the relaxation training (see above).

\section{REM SLEEP AND DREAMS: RESTORATION OF SEARCH ACTIVITY}

If search activity is so important for survival and renunciation of search so destructive, it would be reasonable to assume a natural brain mechanism that can restore search activity after temporary renunciation of search. According to search activity concept, REM sleep and dreams fulfill this function (Rotenberg, 1984; 1993). A covert search activity in dreams compensates for the renunciation of search and ensures the resumption of search activity in subsequent wakefulness. This claim is based on the following findings:

Different forms of animal behavior that contain search activity (self-stimulation, fighting) suppress REM sleep in the subsequent sleep without restorative rebound effect (Cohen et al., 1975; Putkonen\& Putkonen, 1971). This means that less REM sleep is required in such situations.

Renunciation of search causes an increase in REM sleep in subsequent sleep. After an artificially induced freezing the REM sleep proportion in rats considerably increases (Rotenberg \& Arshavsky, 1979b). A correlation was detected between learned helplessness and REM sleep percentage (Adrien et al., 1991; see also Rotenberg, 1996). Acute immobilization stress for 1-4 hours frustrates search behavior and is accompanied by an increase of REM sleep (Cespuglio et al., 1999). Depression is accompanied by the increased REM requirement (REM sleep latency is decreased while the initial REM episodes are increased) (Reynolds\& Kupfer, 1988).

If during REM deprivation, the subject is involved in active behavior (exploration, active defense reaction), REM rebound effect during subsequent sleep is substantially decreased (Oniani \& Lortkipanidze, 1985).
REM sleep, as search activity in wakefulness, is characterized by regular and synchronized hippocampal thetarhythm. Moreover, the more pronounced the thetarhythm in wakefulness, the less pronounced it is in subsequent REM sleep (Oniani et al, 1988). REM sleep in animals regularly contains PGO (ponto-geniculooccipital) waves. In wakefulness, PGO correlates with the orienting activity (Kuiken \& Sikora, 1993).

If nucleus coeruleus aleph in the brain stem is artificially destroyed and as a result muscle tone does not drop during REM sleep, animals demonstrate in this sleep phase complicated behavior, as if they participate in their own dreams, and this behavior can be generally described as orienting (search) behavior (Jouvet \& Delorme, 1965; Morrison, 1982).

Dreams of healthy subjects represent a very specific kind of search activity, which, however, is compatible with the above-mentioned notion of search activity. The subject is active in his/her dream (he/she is struggling, discussing, running, manipulating, reconsidering the situation, etc.) but is unable to make a definite probability forecast according to dream events. A lack of surprise of dreamer in front of dream bizarreness may be the outcome of the lack of probability forecast (Blagrove, 2000).

On the first glance, dream does not apparently fit solely those parts of the notion emphasizing the permanent consideration of the behavioral outcomes. This is true only if the dream is not self-reflective and does not include self-control, and if the activity in the dream is chaotic. However, it was demonstrated (Purcell et al., 1993) that in the vast majority of spontaneous dreams, they are relatively structured, the dreamer is moderately self-reflective and subject can at least partially control his behavior in dream. Dreaming represents a state of attentive awareness without volitional and executive control (Conduit, 2000; Posner \& Rothbart, 1998). Dreams usually are coherent, consistent over time, continuous with past and present waking emotional concerns (Domhoff, 2000; Hall, van de Castle,1966). Selfreflection, decision making and meta-attention are available in dreaming (Kahan, 2000). According to La Berge (2000), it is an almost identical frequency of reflection in dreaming and in waking. A moderate voluntary choice ( $49 \%$ vs. $74 \%$ in wakefulness) is also available during dreaming. According to Vogel (2000), even in dream brain produces organized coherent understandable content. Most dreams are mundane, organized stories, novel, but not very bizarre. Brain mechanisms responsible for error detection, is active during dreams (Solms, 2000), and error detection is a very important component of the brain system responsible for search activity. Permanent consideration of the behavior outcome in dream scenario may display itself in emotional reactions and in periodical alteration of this scenario. 
Dreams are a good opportunity for search activity after giving up in wakefulness. First, the subject is separated from reality while sleeping, including those aspects of reality that caused renunciation of search. The subject is free to start from the beginning. Second, within his dream, the subject is very free in his decisions: he can try to solve his problem in a metaphoric manner, or he can solve another problem, one that displaces the actual problem, since the search process itself is the main restorative factor and the direction of search activity is not important. It was shown (Montangero, 1993) that although REM sleep and dreams play an important role in the solution of creative problems, the problem itself is not solved in dreams. When the creative task was successfully carried out on the following morning, it was related to the self- representation of dreamer as a successful problem solver. Thus a dream can participate in problem solving indirectly, independently of the presence or absence of the actual problem in the dream content. A different problem may be solved in the dream, and the process of solving of this unrelated problem might restore the search activity and help the subject to solve the actual problem in the subsequent wakefulness. Healthy subjects are characterized by active participation in their own dream scenario and by the heart rate acceleration in REM sleep that correlates with selfparticipation (Rotenberg, 1988). The more characters and descriptive elements appear in the dream, and the more active the characters and the dreamer himself, the larger the decrease in the scale of unhappiness during the night (Kramer, 1993). It can be suggested that active characters represent search activity in dreams. It is necessary to emphasize that in healthy subjects the decrease of the level of unhappiness after the night sleep correlates only with the above mentioned dream variables, not with the changes in sleep structure and REM sleep percentage. This means that as long as the dream quality is functionally effective (sufficient) and is able to restore search activity, REM sleep duration and REM sleep latency are not affected substantially. However, REM sleep requirement is increased in clinical disorders like depression, when dreams lose their restorative capacity (Rotenberg, 1988; Rotenberg et al., 1997a;b). REM sleep duration is also higher in long sleepers in comparison to short sleepers, the former being characterized by higher emotional sensitivity and predisposition to anxiety, sub-clinical depression and reactions of surrender (Hartmann, 1973).

In healthy subjects, eye movement (EM) density in REM sleep correlates with the active participation of dreamer in his dream scenario (Rotenberg, 1988) and with visual imagery in dreaming (Hong et al., 1997). Thus, EM density in healthy subjects may correspond to the search activity in dreams. In healthy subjects EM density regularly increases from the first to the last REM sleep period, and it corresponds with the restora- tion of mood from evening to morning. Interestingly, even in depressed patients mood improves in the morning in comparison to evening if EM density increases from the first to the fourth cycle. However it happens rarely, less than in $20 \%$ of all nights (Indursky \& Rotenberg, 1998). Moreover, if in depressed patients the initially low slow wave sleep (SWS) suddenly increases in the last sleep cycles, such "explosion' of SWS is preceded by the increase of EM density in the previous REM period (Rotenberg et al., 1999). This increased phasic activity in REM sleep may reflect the activation of the restorative function of REM sleep, which creates a condition for the secondary restoration of SWS.

\section{REM SLEEP/TOTAL SLEEP DEPRIVATION}

Data of sleep/REM sleep deprivation in animals confirm the proposed REM sleep function of the restoration of search activity. This topic requires a more detailed discussion.

There are three methods of REM sleep deprivation: pharmacological, behavioral (placing the animal on a water-surrounded or rotating platform), and electrophysiological (direct stimulation of the midbrain reticular formation at the very beginning of each REM sleep episode). We will discuss only the latter two methods because the pharmacologically induced deprivation effect cannot be separated from the direct impact of the pharmacological substance on the brain.

The method of the small platform (Jouvet, 1965) should provoke the frustration of free search activity and finally the renunciation of search. In this condition the inability to change the situation and even to make efforts in this direction is combined with the irremovable aversive impacts caused by the fall into the water at the onset of every REM sleep episode. Such condition finally produces learned helplessness (LH) and increases the requirement in REM sleep. At the same time, compensation for this state in REM sleep is impossible due to the REM sleep deprivation.

When the animal after 72-96 hours of deprivation is removed from the platform and placed in conditions where nothing prevents behavioral activity, the latter exhibits a variety of forms ranging from intensified selfstimulation to an increase in the number of runs in the open field, hyper-sexuality and hyperphagia. It looks like a rebound of frustrated activity (including search activity). After longer deprivation periods animals demonstrate a drop of their activity, of exploratory behavior and of somatic resistance and display somatic disturbances, hemorrhages in the gastric epithelium, and gastric ulcers. It is a state of LH. Finally, they may even die (Current Research of Sleep and Dreams, 1966). Mollenhour et al. (1977) showed that the number of relevant aggressive behavioral reactions stimulated by electric shock increases only for ninety-six hours of the deprivation period and then declines. An equally long depriva- 
tion interferes with the learning of active avoidance, which can be restored by an imipramine injection (Stern \& Morgane, 1974). Mollenhour et al. (1977) assumed that prolonged REM sleep deprivation leads to the exhaustion of the brain catecholamines (see later). Interestingly, the same non-monotonous relationship between the duration of the treatment and behavior characterizes the development of learned helplessness: after the initial exposures to inescapable shocks the animal became overactive in the open field while later behavior became passive and learned helplessness appears (Overmier \& Seligman, 1981).

At the same time, if frustration of search behavior is created only by acute immobilization without sleep deprivation, such immobilization leaves the character of behavior in the open field unaffected (Rotenberg, Kovalzon \& Tsibulsky, 1986). This can be interpreted as evidence of the compensatory role of REM sleep, because acute immobilization for 1-4 hours is accompanied by an increase of REM sleep episodes (Cespuglio et al., 1999). Immobilization for more than 4 hours causes sleep disturbances (as a sign of distress) and deterioration of the adaptive brain mechanisms (Cespuglio et al., 1999).

It is worth to discuss why on the small platform learned helplessness (LH) appears only after 96 hours, while in investigations using traditional methods (foot-shocks) it appears much earlier. One possible explanation is that on the small platform the conditions for LH (the restriction of free behavior, the frustration of REM sleep requirement, and irremovable aversive impacts) are combined with a regular experience of active avoidance. During wakefulness, rat is continuously mobilized in order not to fall into the water. During sleep rat regularly falls in the water and makes efforts to climb back on the platform. This experience of active avoidance is opposite to the experience producing LH and may contribute to the delay of its development. In addition, the deprived REM sleep may be partly compensated by REM sleep phasic elements incorporated in NREM sleep (see Nielsen, 2000).

Total sleep deprivation or REM sleep deprivation on the rotating wooden platform (Rechtschaffen et al., 1983; Everson, 1995) displays some similarities with the deprivation on the small platform according to the conditions which prevent search activity. While this is not a complete immobilization, animals' free behavior in this condition is restricted and search activity is almost completely blocked. Rats developed a progressive negative energy balance and sympathetic activation without over-activation of the stressor system, and are dying during 3 weeks due to chronic internal septic state caused by immunosuppression. Control rats were also partially REM sleep deprived and demonstrated the same dynamic of physiological functions as experimen- tal rats do, but these alterations of physiological functions were less prominent.

Thus, although sleep deprivation on the rotating platform is not accompanied by acute distress, it has a negative slowly developed influence on body resistance. Absence of search activity during wakefulness and sleep causes a suppression of the immune system (Rotenberg et al., 1996). In addition, experimental animals are regularly frustrated in their attempts to satisfy their natural need for sleep and for REM sleep. Such regular frustration serves as an unavoidable punishment, eventually leading to learned helplessness. As a result, the need for REM sleep increases, but REM sleep is suppressed. Such a combination of the increased requirement for search activity with REM sleep deprivation can help to explain the main outcomes of total sleep deprivation. Everson (1995) found that for those animals that survived the prolonged platform sleep deprivation, recovery sleep was marked by a dramatic rebound of REM sleep. NREM sleep rebound was not observed although most of the lost sleep was of the NREM sleep type. This means that in these conditions the requirement for REM sleep caused by the combination of sleep deprivation and the frustration of behavioral search activity is more important for the organism than the requirement for NREM sleep. Moreover, after the REM sleep rebound the symptomatic of the prolonged sleep deprivation is quickly reversed and health is restored. Even among the control animals in the gravest functional state was the rat that showed the shortest REM sleep. These findings strongly suggest that the symptomatic (decreased host defense) is related to the lack of renewal of search activity during deprivation.

At the same time, electrophysiological deprivation of REM sleep, accomplished in comfortable conditions with the opportunity to satisfy all biological requirements, in contrast to REM deprivation on the small platform, neither influences the intensity of self-stimulation nor changes the character of behavior in the open field. There is even some tendency toward a diminution of exploratory activity and emotional reactivity (Kovalzon \& Tsibulsky, 1984). In an animal that gets into a completely comfortable situation and can effortlessly satisfy its basic requirements in the process of non-restricted behavior search activity seems to be less obligate.

The animal in such cases is unmotivated to change its situation or is even motivated not to change it. In this artificial condition, REM sleep seems to be less obligate because the requirement in search activity is low and subject is not in the state of renunciation. Electrophysiological REM sleep deprivation in this situation does not cause stress although preventing subject from the last opportunity of search activity. However, a state such as this, despite its relatively comfortable character, is hardly useful biologically. Kovalzon and Tsibulsky (1984) have shown that in the case of electrophysiological 
REM sleep deprivation there is a decrease in the activity of the nonspecific stressor system compared to the background, a drop in the weight of the adrenal gland and an increase in that of the thymus. As long as the comfortable situation is maintained, it is not dangerous. However, any threat or obstacle can bring on a catastrophe due to a drop in the reserve potential of the stressor system. If REM sleep is not deprived, the activity of the nonspecific stressor system does not drop.

Thus, REM sleep compensates for the search activity deficit both in the case of renunciation of search and in that of a temporarily decreased requirement in search activity and "trains" the search activity mechanisms.

\section{ONTOGENESIS AND PHILOGENESIS}

Data pertaining to the functional significance of "active" sleep in ontogeny indirectly confirm the basic propositions of the search activity concept. During the early stages of ontogenesis of newborn babies, in the absence of prerequisites of overt search behavior the greatest proportion of sleep is active sleep whose many indicators resemble those of the REM sleep of adults. Adult rats exhibited a change both of waking and of sleep (Mirmiran et al., 1981) after prolonged pharmacological suppression of active sleep at an early age. Behavior in waking was characterized by the weakening of exploratory and sexual activity, a deterioration of learning, except for passive avoidance, and an increase of anxiety level (defecation). Simultaneously, rats showed longer REM sleep accompanied by increased amplitude of the hippocamal theta-rhythm and intensive eye movements. Thus, suppression of "active" sleep in early ontogeny subsequently led to a drop in search activity in waking. The REM sleep increase reflects the insufficient attempt to overcome this outcome.

Of a great interest are data concerning the philogenesis of sleep. Animals whose behavior in waking is relatively simple are distinguished from other mammals by a number of specific features. First, they are sufficiently developed at birth having practically no experience of helplessness at the early stages of ontogeny. Second, they exhibit poor adaptation to unusual new conditions. Third, their REM sleep percentage in an adult state is lower (Kovalzon, 1976). From birth such animals have no right to helplessness as potential victims of predators. Accordingly, the state of the postnatal evolution of their central nervous systems is reduced. In general, the longer is the state of the post-natal development of brain prior the full maturation, the higher is the level of the adaptive brain functions. Thus, in herbivorous, the potential victims of predators these functions reach a lower level of organization than those of other mammals. These animals are adapted to customary conditions; however adaptation to unorthodox condition requires search activity. Meanwhile, mammals whose behavior is determined by search activity must have safe mechan- isms (REM sleep) that guarantee its restoration in critical situations, after an occasional giving-up reaction, especially in view of the more complex behavior and experience of helplessness in ontogeny.

It is one paradoxical fact worth to discuss. This fact is the absence of REM sleep in such a highly developed animal as the dolphin (Mukhametov, 1988). If REM sleep is obligate for memory functions in mammals (see later), it is difficult to explain an absence of this state in dolphin with its high intellectual and memory skills. Search activity concept presents an explanation of this phenomenon. In the natural conditions the dolphin maintains constant active interaction with the environment. This contact with the environment continues unabated throughout twenty-four hours since the dolphin sleeps now with its left, now with its right hemisphere, one of the two remaining constantly awake. Apparently, the state of renunciation of search is not biologically inherent in a dolphin, and this animal need not REM sleep in order to compensate this state. An indirect confirmation of this hypothesis is the fact that dolphins find it very difficult to adapt themselves to forms of captivity that limit the possibility of active behavior. If they fail to go over to a new behavior type, such as active interaction with the experimenter, these highly intellectual animals soon die.

\section{BRAIN MONOAMINES, BEHAVIOR and REM SLEEP}

Literary data according to this topic are very complicated and controversial. On the one hand, some data suggest that the degree of the expression of search activity is directly connected with the level of brain monoamines (norepinephrine, dopamine etc.). Thus, passive behavior caused by unavoidable aversive stimulus out of the animals' own control and accompanied by somatic disturbances is observed only in the case of a drop in the brain norepinephrine level (Miller, 1976). Anisman and Zacharko (1982) proved that if the aversive stimuli induce coping behavior, this is accompanied by an intensified utilization and synthesis of brain monoamines. When such behavior is impossible (like in the state of renunciation of search) the utilization of amines intensifies, exceeding their synthesis. The main function of the locus coeruleus, a basic element of the brain noradrenergic system, is the assessment of the significance of an indefinite situation and the mobilization of the organism in the conditions of such indefiniteness (van Dongen, 1981). This corresponds to the author's definition of search activity. The locus coeruleus is relatively quiescent during feeding and sleep (Brunello, 2000).

Concerning the relationship of the brain monoamine system to search behavior, the following hypothesis has been developed (Rotenberg, 1984, 1994) Search activity can start in the presence of a certain critical level of the 
brain monoamines, which are utilized in the course of search behavior. Search activity itself, once it starts, further stimulates the synthesis of the brain monoamines and ensures their availability. Thus, the more pronounced the search activity, the sooner the turnover of the brain monoamines can be compensated for by resynthesis, in turn maintaining search behavior (positive feedback system). It is well known, that the firing activity of brain catecholamine (in particular, norepinephrine) neurons is under a negative feedback control by cell body alpha-2-adrenoreceptors (Blier et al., 2000). Thus, it is possible to suggest that particularly in wakefulness characterized by the prominent search activity alpha-2-adrenoreceptors became less sensitive to stimulation and as a result only in this state the activity of the brain monoamine neurons is less limited by the level of brain monoamines. Such desensitization of the alpha-2-adrenoreceptors provides an opportunity for a high constructive activity - search activity.

In a state of renunciation of search, the abovementioned positive feedback system does not function. Furthermore, in this state the monoaminergic expenditure becomes faster, and brain monoamines (dopamine, norepinephrine, serotonine) have a tendency to drop, as it happens in learned helplessness (Seligman, 1975). The present author proposes that renunciation of search is characterized by the relative hypersensitivity of alpha-2-adrenoreceptors, in comparison to search activity. As a result, even a relatively low level of brain monoamines suppresses the activity of the monoaminergic neurons. Renunciation of search is usually combined with distress, as a reaction on the threatening condition. Distress causes intense monoamine expenditure, without any constructive activity and profitable outcome for the organism. Thus, according to this hypothesis, monoamine functioning completes a vicious circle: renunciation of search leads to a drop in the brain CA level, which in turn leads to the renunciation of search's becoming more prominent.

Stress (either distress or eustress), is accompanied by the activation of the hypothalamic-pituitary-adrenal (HPA) axis, the system that manages the body response to stressful conditions and prepare subject to active behavior. However, distress (renounce of search) is not accompanied by such active and appropriate behavior, thus HPA axis is strained in an idle way without being used constructively. Being not realized in an appropriate behavior the strain of the HPA axis is not released and is going to increase further. As a result, the increase of the corticotropin-releasing factor (CRF) is accompanied by the paradoxical increase, instead of decrease, of the CRF receptor density in certain brain regions (Nemeroff, 1998). Finally, the hyperactivity of the HPA axis is leading to somatic disorders.

Relationships between brain catecholamines and REM sleep are even more complex and contradictory. On the one hand, a considerable drop in the brain norepinephrine level, blockade of its synthesis, or inhibitions of its release leads to a decrease in REM sleep time (Putkonen, 1979). However, alpha-adrenergic stimulants and antidepressants also reduce REM sleep time (Putkonen, 1979; Mendelson et al., 1977; Gaillard, 1979). At the same time, the noradrenergic neurons of locus coeruleus as well as seroninergic neurons of raphe tremendously decrease their activity in REM sleep, not only in comparison to wakefulness, but even in comparison to NREM sleep (Hobson et al., 2000). In discussing the correlation between the brain's catecholamine system and REM sleep, Gaillard (1979) singles out three basic problems:

The brain's catecholamine system participates in the organization of both waking and REM sleep. These two functional states are different whereas the difference in the character of functioning of the norepinephrine system remains undisclosed.

There is no simple relationship between the level of endogenous monoamines and that of cerebral vigilance and REM sleep representation. In particular, reserpine reduces the brain catecholamine level but increases the REM sleep phase.

The majority of antidepressants inhibit the reuptake of monoamines, at the same time suppressing REM sleep.

However, a careful analysis of experimental data makes it possible to establish a definite curvilinear regulation (Rotenberg, 1994). REM sleep increases along with a moderate reduction of monoamine (norepinephrine) system activity (Kafi et al., 1977). More pronounced inhibition of this system's activity leads to the suppression of REM sleep (Kafi et al., 1977; Gaillard, 1979). Small and moderate doses of neuroleptics increase the total REM sleep time, whereas large doses decrease it. (Mendelson et al., 1977) However, stimulants of the monoaminergic system also reduce REM sleep time (Putkonen, 1979), and, as we have stressed, it is reduced in the process of search activity. Thus, it is possible to suggest that the optimal brain monoamine level is lower for REM sleep functioning than for the organization of active waking behavior (Gaillard, 1985).

Search activity concept attempts to overcome all these contradictions. In the case of the low search activity (in particular, in renunciation of search), as we have stressed, brain CA drop and the restoration of brain CA level requires compensatory search in REM sleep. There are reasons to believe that the above-critical level of brain CA for search activity to start is in REM sleep lower than in wakefulness (Cohen, 1979). The state of renunciation of search begins before the excessive fall in brain CA level. When in this state waking passes into sleep the brain CA level is still high enough for search activity to begin in REM sleep. However, it is no longer high enough to enable man or animal spontaneously to overcome renunciation of search in waking as long as 
the renunciation-provoking conditions are at work. Physiological conditions in REM sleep and dreams may be favorable for the initiation of search activity even in front of the low activity of CA neurons in locus coeruleus. It is very possible that search activity in dreams is related to the activity of dopamine neurons in neocortex (Solms, 2000). This hypothesis is close to the suggestion of Panksepp (2000) that REM sleep normally sustains the synaptic efficacy of neurotransmitters.

Recently I have proposed a new hypothesis of brain CA activity in REM sleep (Rotenberg, 2006). This hypothesis partly includes the hypothesis of Siegel and Rogawski (1988) that the inhibition of activity of NE containing cells in REM sleep is required to maintain the sensitivity of NE postsynaptic receptors that became decreased during wakefulness. However, the cornerstone of the new hypothesis is the review of Gottesman (2002) according to the role of different monoamines in mental activity, particularly in REM sleep. According to this review, acetylcholine (Ach) is responsible for the general activation of cortical neurons initiated by the reticular activating system of the brainstem as a nonspecific predisposition to the goal-oriented selective activity that requires differentiation between meaningful and meaningless information elicited by the environment. Such discrimination (that is very important for the search activity in wakefulness) is based on the partial flexible inhibition of cortical neuronal activity and on the increase of signal-to-noise ratio that makes neuronal activity task-relevant. NE and serotonin (5-HT) in wakefulness are responsible for this partial cortical inhibition, while dopamine (DA) plays an important role in novelty seeking, exploratory behavior, attention and excitement in response to novel stimuli.

According to my hypothesis search activity in wakefulness is based on the combination of activating (Ach and DA dependent) and inhibitory (NE and 5-HT dependent) influences on cortical neurons. This combination determines the regulation of search behavior, its goal direction, its relative restriction according to the actual tasks and its relevance to the objective reality. Due to this regulative inhibitory influences search activity in normal wakefulness although relatively flexible, is neither infinite nor omnipotent: it has limits.

In REM sleep, due to the cessation of the inhibitory NE and 5-HT neurons and the absence of its modulating activity, search activity being based exclusively on the DA system became free, unrestricted, labile and almost chaotic. It displays itself i8n dreams. If search activity in dreams is based predominantly on the nonmodulated activity of DA system, it has a lot of advantages. First of all, it makes search activity in dreams unrestricted and almost omnipotent. Secondly, the temporal cessation of NE and 5-HT activity in REM sleep may help to restore the sensitivity of the postsynaptic receptors, as Siegel and Rogawski proposed, and the restored sensi- tivity of these systems is very important for the well regulated and goal directed search activity in the subsequent wakefulness.

Search that becomes enacted in REM sleep switches on the system with a positive feedback, where search activity ensures its own continuation, as in wakefulness. As a result, the subject awakens ready for search and the situation that has provoked renunciation is no longer perceived as hopeless.

\section{REM SLEEP, BEHAVIOR AND MEMORY}

The outlined ideas concerning the function of REM sleep and dreams can help to solve many debatable problems of sleep psychophysiology. Among such problems, in particular, is the role of sleep in memory and learning. Many authors (McGrath \& Cohen, 1978; Pearlman, 1979; Smith, 1985; 1993; Stickgold, 1998) suggest that REM sleep per se plays an important role in the consolidation of unusual and emotionally significant information, but not in the retention of ordinary information. However, it was shown that the creative (unusual) task in most cases is not solved in REM sleep per se (Montangero, 1993). REM deprivation after training had no effect on declarative/explicit tasks such as word recognition task (Conway \& Smith, 1994) but hindered subsequent performance of implicit/procedural tasks such as word fragment completion task, mirror writing and the Tower of Hanoi task (Smith, 1995). REM sleep deprivation does not influence the learning process, if the learning prior to the deprivation was performed with intensity and success and the task was realized during wakefulness (McGrath \& Cohen, 1978). There are some arguments against the idea of the direct participation of REM sleep in the consolidation mechanisms: 1. During the active search behavior in the stressful situation, the consolidation of the new experience is essential for the organism, but REM sleep during this form of behavior does not increase, and even decreases (see above). 2. The REM sleep percentage increases due to neuroleptic treatment (Mendelson et al., 1977) but does not have a beneficial effect on memory. 3. Activating drugs, like amphetamine, have a tendency to suppress REM sleep but at least do not disturb memory (Coenen \& van Luijtellar, 1997).

However, it has been shown that REM sleep grows longer at certain stages of the solution of emotionally significant complex problems, which the animal or human subject is originally unprepared to handle (McGrath \& Cohen, 1978). There is evidence suggesting that the greatest increase of REM sleep occurs during the 24 hours before the critical level of success in the learning process (Leconte et al., 1973; Pagel et al., 1973). REM sleep deprivation carried out directly in this period impedes it. It is possible to suggest that REM sleep is especially important for the animal during the critical period of an acute conversion from the pre- 
vious stereotypical behavior to the new style of behavior.

It might be a sign that REM sleep plays only an indirect role in the process of retention by carrying out its main function - compensation of renunciation of search and restoration of search activity (Rotenberg, 1992). A complex problem that the subject is not ready to solve, a difficult task that requires unprepared learning may cause renunciation of search with much greater probability than a simple one, especially at the early stages of the solution when failures prevail over successes. In experiments on animals " the learning situation imposed is undoubtedly the most important and traumatic event in the life of the organism" (Smith, 1993, p.342), and such event has a big chance to produce a giving up reaction (renunciation of search). Actually, the non-learning rats (rats that remain below the learning criteria) displayed a large majority of freezing responses during training and had thereby received the highest number of electric shocks (Giuditta et al., 1995). If search activity in REM sleep is unavailable (due to REM deprivation) and consequently does not overcome the state of renunciation of search, the latter itself will make it impossible to find the right solution or keep it in memory. REM deprivation after training leaves memory in a labile form and delays the process of consolidation (Fishbein, 2000) presumably due to domination of the maladaptive state of renunciation. Therefore, the lengthening of the REM sleep directly before the critical point in the learning, after which the animal fully develops the habit, is not surprising. However, in some cases the lengthening of REM sleep may be found to be not enough to compensate for the state of renunciation of search, if the latter is very strong. In these cases REM sleep may increase in those animals that are the least successful in forming the new habit (Fishbein et al., 1974). On the other hand, usually in non-learning rats the compensatory REM sleep system seems to be weak and insufficient (see the next chapter). This hypothesis is based on data (Giuditta et al., 1995) that the average duration of REM sleep episodes of baseline sleep of non-learning rats is significantly shorter in comparison to learning rats. Stressful conditions of training may cause a further suppression of REM sleep instead of its activation.

According to the dynamic of neuronal activity, information flows in similar directions - from neocortex to hippocampus - in REM sleep and during active exploration in wakefulness (Stickgold, 1998). It confirms our conclusion about active exploration in REM sleep. In addition, it means that according to the memory consolidation brain is working in a similar way in REM sleep and during active exploration in wakefulness. It is possible to suggest that the more successful is memory consolidation during wakefulness (for instance, after active exploration, or active defense reaction, or after using amphetamine) the less important is REM sleep for the same function. Thus, the requirement in REM sleep increases if memory consolidation during wakefulness is less efficient. This explanation still prescribes memory function to REM sleep. However, it is already very close to the above explanation of the indirect contribution of REM sleep in memory function. It is renunciation of search making any functions in wakefulness, including memory, less efficient. Going further, this approach provides explanation for data being difficult to explain by the concept of memory consolidation in REM sleep. For instance, what is the functional meaning of the REM sleep increase after immobilization stress or learned helplessness?

What sort of information is it necessary to consolidate by mean of REM sleep after such experience? Subject needs only to overcome the unproductive state of renunciation of search created by these conditions. Thus, the concept of the indirect positive role of REM sleep in memory functions seems to be more comprehensive and broad.

It was shown recently (Maquet et al., 2000) that several brain areas activated during the execution of a serial reaction time task during wakefulness were significantly more active during REM sleep in subjects previously intensively trained on the task than in non-trained subjects. In addition, this task was performed better after sleep than before sleep. According to the authors, these results support the hypothesis that memory traces are processed during REM sleep in humans. However, the same brain structures may be involved in search activity during training in wakefulness and in REM sleep. Secondly, it was shown (Greenberg et al., 1992) that dreams may represent in a very direct way the previous waking experience and problems subject was preoccupied with in previous wakefulness. If subjects have been involved in task performance (and even periodically failed in this performance) they can imagine this task in dreams and the relevant brain area may be activated during such imagination, as it happens during the imaginations in wakefulness. Does it really mean that such imagination contributes in memory consolidation? If it would be the case, all tasks, not only the difficult one, would be sensitive to REM sleep deprivation. In addition, usually people do not see in their dreams the elements of information they have to consolidate in their memory.

A long REM sleep deprivation on the wooden platform before learning destroys simple active avoidance (Stern, 1971) while a short REM deprivation can even stimulate active avoidance (Oniani \& Lortkipanidze, 1985). If REM deprivation is short, then search activity is frustrated, but brain monoamines and physiological mechanisms responsible for search activity are not yet exhausted. The change from the frustrating conditions on the wooden platform to the conditions of learning and testing may cause a rebound of motor activity and 
search activity (see above). Such new condition can even promote some forms of learning, for instance, active avoidance. Conversely, if REM deprivation is prolonged, a renunciation of search activity appears, and the whole process of learning is destroyed. Memory traces than become more sensitive to disturbing influences. Thus, REM sleep deprivation before learning creates a distress that can interfere with memory.

\section{FUNCTIONALLY SUFFICIENT VS. FUNCTION- ALLY INSUFFICIENT REM SLEEP}

In order to perform its main function - restoration of search activity - REM sleep has to be functionally sufficient. In the functionally sufficient REM sleep dream events contain a prominent search activity. In healthy subjects, and especially in those with high emotional sensitivity and vulnerability, the requirement in the restorative function of REM sleep is high, their dreams are vivid and dreamer is usually active in his dreams (Foulkes \& Pivik, 1966; Cohen, 1974; Rotenberg, 1982). Cartwright et al., (1998 a, b), found that in healthy subjects dreams in the first REM sleep period are influenced by the presence of negative mood prior to sleep. Subjects with some pre-sleep depressed mood showed a pattern of decreasing negative and increasing positive affect in dreams reported from successive REM periods. It was in parallel with significant mood improvement during sleep (see also Kramer, 1993). According to Cartwright et al., 1998b, the reduction of negative mood from the first to the last REM sleep period may reflect a psychological, across-the-night "working through" dream process which in my terms corresponds to search activity. However, in subjects with different mental and psychosomatic disorders REM sleep exhibits essential qualitative differences from what it is in healthy individuals. REM sleep is characterized by the decreased number of dream recalls, short dream reports and low level of dreamed activity (Kolucy et al., 1976; Kramer, 1970; Golbin, 1979; Escalate, 1989; Berger et al., 1988; Rotenberg \& Biniarishvili, 1973; Rotenberg, 1980; 1982; 1988; Riemann et al., 1988; Armitage et al., 1995). In depressed patients in dreams, as in waking, the feeling of helplessness dominates, and the individual's active position in dreams is absent. Dreams of suicidal people represent painful feelings of hopelessness and helplessness, reactions of surrender and giving up as well as fixation on obstacles (Weinberg, 2000). A passive position of dreamer in depression displays itself also in the domination of masochistic dream type (Kramer, 1993).

All these changes are signs of the weakening of search activity in REM sleep. This sleep may then become not simply useless, but even harmful: during emotionally saturated dreams in which the renunciation of search continues instead of being overcome, the adaptive brain mechanisms become further exhausted instead of refilling, and state of giving up dominates.

The present author suggested that the decreased dream activity and disappearance of dream reports is an important mechanism of pathogenesis of mental disorders (Rotenberg \& Biniaurishvili, 1973; Rotenberg, 1988). Greenberg (1977) also proposed that dreams of depressed patients, in contrast to dreams of healthy subjects, are maladaptive.

Patients and healthy subjects display different correlations between dream mentation and physiological variables in REM sleep. In healthy subjects eye movement (EM) activity display a regular increase from the first to the last REM sleep period and its density correlates with dream content (Hong et al., 1997), in particular with subject's active participation in his own dreams (Rotenberg, 1988). It is possible to suggest that in healthy subjects EM density is a sign of search activity in dreams that normally increases from cycle to cycle. This suggestion is in a good agreement with data (Kramer, 1993) that the normal sleep of healthy subjects determines the restoration of mood from evening to morning. However, in depressed patients EM density correlated with the subjective estimation of the number of awakenings, and EM density in the first cycle correlated with the subjective estimation of sleep latency (Rotenberg et al., 2000a). Patients with chronic schizophrenia display a positive correlation between estimation of the duration of wakefulness during the night and EM density in the 4th cycle and a negative correlation between EM density and dream reports (Rotenberg et al., 2000b). Thus it is possible to suggest that in mentally ill patients psychic activity in REM sleep, if present, is often not perceived as dream mentation, but is considered subjectively as wakefulness. It confirms functional insufficiency of REM sleep.

Depression and some other mental disorders are characterized by the decreased REM sleep latency and increased REM sleep pressure (Benca et al., 1992). It means that the requirement in REM sleep in these disorders is high. However, if REM sleep is functionally insufficient, even the increase of this state does not help to restore search activity and has no adaptive values.

Of course, functional insufficiency of REM sleep in mental and psychosomatic disorders is only a general tendency. It would be a mistake to insist that REM sleep is always insufficient and a physiological variable in all cases does not represent normal dream activity. The picture is more complex. As we have already stressed before, mood in depressed patients after almost $20 \%$ of all nights is better than in the evening, and in such cases EM density has in average a normal dynamic: an increase from the first to the last REM sleep period. In most other nights EM density is higher in the first cycle (Indursky \& Rotenberg, 1998). However, the increase of EM density from cycle to cycle is also not obligate 
for REM sleep efficiency. For instance, we have shown (Rotenberg et al., 1999) that in depression the restoration of the deficient slow wave sleep (SWS) in the last cycles is regularly predicted by the increase of EM density in the previous REM sleep period. Such increase may correlate with an adaptive ability of REM sleep. When REM sleep in the second part of the night is functionally sufficient it usually contains increased EM density. However, the inverted assumption is not correct: the increase of EM density is not followed regularly by SWS increase. It means that the low EM activity in the second part of the night is usually a sign of REM sleep insufficiency, but the increase of EM density by itself is not a definite sign of REM sleep functional sufficiency or insufficiency. The same is true for the autonomic functions in REM sleep. For instance, the variability of heart rate in REM sleep in healthy subjects correlates positively with the participation of dreamer in his dream scenario, and in neurotic patients negatively (Rotenberg, 1982).

Thus, it is difficult to estimate the functional sufficiency/insufficiency of REM sleep purely on the basis of physiological variables. ( I know only one exception: decreased heart rate in REM sleep in comparison to the previous sleep stages is usually related to the low dreamer's activity in dream (Rotenberg, 1982; 1988).

It means that although there are some correlations between REM sleep variables and dream mentation, REM sleep and dreams are controlled by different systems. According to Solms (2000), brain stem mechanisms control REM sleep as a physiological state, while dreams are controlled by the forebrain mechanism that can be activated during REM sleep, but also can be not activated. The physiological investigations of sleep do not allow making any definite conclusions about the functional sufficiency/insufficiency of REM sleep, and it may be a reason of many contradictions in the experimental data. For instance, it is well known that REM sleep deprivation in healthy subjects causes often psychological disadaptation (Greenberg et al., 1970; Grieser et al., 1972), however the same method is used for the treatment of depression (Vogel, 1980). The functional insufficiency of REM sleep in depression can explain the positive effect of sleep/REM sleep deprivation, especially if sleep deprivation by itself is accompanied by some stimulating tasks which can enhance search activity.

According to some recent investigations (see Rotenberg, 2008) melatonin stimulates the dopamine system responsible for REM sleep-dreams sufficiency.

Functional insufficiency of dream activity reflects the weakness of the polysemantic image thinking related to the right hemisphere (Rotenberg, 1993; Rotenberg, 1996). However, it is a special topic that requires another target article.

\section{CLINICAL APPLICATIONS OF THE SEARCH ACTIVITY CONCEPT: ADAPTIVE vS. MALA- DAPTIVE ANXIETY.}

Emotional tension can be either maladaptive or adaptive in both nature and outcome. Adaptive emotional tension helps subject to solve problems and to overcome obstacles and have no negative outcome on health. Despite the theoretical and practical importance of the distinction between adaptive and maladaptive emotional tension, neither adequate theoretical approach nor valid methods appear in past research to distinguish between the two.

According to general activation theory, an optimal level of emotional tension is adaptive in helping the individual to solve problems and to overcome obstacles without any negative outcome for the organism. If the level of tension is extremely low or high, its outcome is regarded as negative with respect to performance, adaptation and health. It is the Yerkes-Dodson law (Yerkes \& Dodson, 1908; Lens \& DeVolder, 1980).

Nevertheless, there are many exceptions to the YerkesDodson law. First, pathological emotional tension (neurotic anxiety) is always harmful, with respect not only to the health but also to performance, thereby decreasing the effectiveness of the latter in a linear manner (Spielberger, 1962; Lader, 1975). On the other hand, even a very high level of emotional tension can promote the activity of the subject. (Fig. 2) According to Dienstbier (1989), naturally evoked peripheral catecholamines never seem to be too high for optimal performance. In addition, when methods of coping were available, even very high arousal levels failed to elicit discomfort and negative emotions (Gal \& Lazarus, 1975).

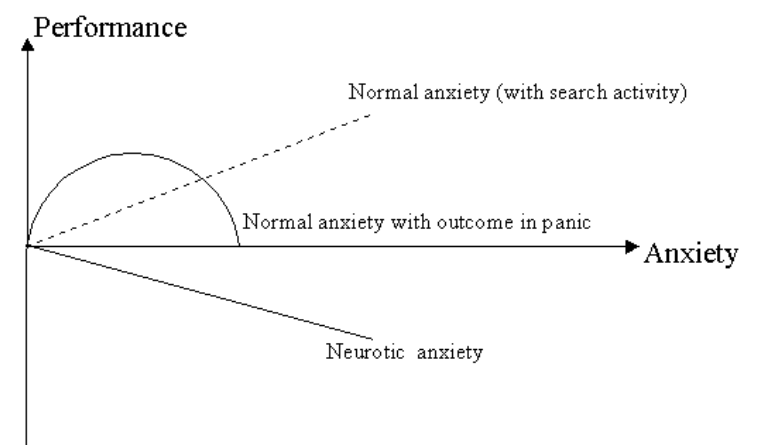

Figure 2. Different forms of emotional tension (anxiety) and performance

I suggest that the difference between productive emotional tension (the normal anxiety of a healthy individual in a state of stress), instrumental in mobilizing all psychological and physical resources to overcome obstacles, and unproductive emotional tension that hampers successful activity is determined by the presence or absence of search activity in the structure of emotional 
tension (Rotenberg \& Boucsein, 1993). Until search activity is present, anxiety is adaptive. All forms of maladaptive anxiety (like panic and neurotic anxiety) do not correspond to search activity, both according to the theoretical notion and clinical observations. As it was stressed previously, during a panic the results of the activity are not considered at any stage and cannot be used for the correction of behavior. Panic behavior during catastrophic events is usually displaced by or combined with depression (Zuckerman, 1984; Rosenbaum, Seligman, 1989). Panic may represent an exaggeration of normal anxiety that corresponds to the final point of the curvilinear line displaying relationships between emotional tension and adaptation or performance (see Figure 2). In this final point the emotional tension is very high while performance and adaptation are low. This happens in particular when vital motivations are increased and fear of the consequences of failure deteriorates behavior. In panic, like in other states of emotional tension without search activity, the expenditure of brain catecholamines exceeds their synthesis, and eventually there comes a pronounced drop in their levels and a secondary depression. Neurotic anxiety, according to the psychodynamic conception, is a consequence of the repression of an unacceptable motive from consciousness. The repression can be regarded as a purely human variant of renunciation of search of the modes of realization of the unacceptable motive in overt behavior and modes of integration of it with other, realized behavioral orientations.

Benzodiazepines have different outcome on adaptive and maladaptive emotional tension. It is well known, that benzodiazepines sometimes enhance and sometimes diminish the motor response to a threatening signals (Gray, 1982). In moderate doses, they do not block active avoidance or even increase it, but they usually block freezing as a sign of renunciation of search (Soubrie, 1982). Maladaptive anxiety is more sensitive to anxiolytics, and because of the competition between renunciation of search and search behavior, freezing can be replaced by active avoidance.

Search activity concept helps to solve some contradictions related to autonomic patterns in different forms of anxiety. Thus, there is a marked difference between the habituation of orienting reaction (OR) in healthy subjects versus subjects with psychopathology. In healthy subjects, the amplitude of the electro-dermal reaction (EDR) during the first two OR's is higher and the habituation is faster while a spontaneous electro-dermal activity is lower (Lader, 1979 ). If the spontaneous electro-dermal activity reflects an inner emotional tension not relevant to the external task, and the evoked EDR reflects the emotional tension during decision making (Rotenberg \& Vedenyapin, 1985) it can be suggested that pathological subjects are overwhelmed by their emotional tension, which causes hyperarousal. This high arousal, however, reflects maladaptive emotional tension, is in competition with search activity and blocks normal forms of behavior requiring search activity, in particular, orienting reaction. From my point of view, it is a more reasonable explanation than the explanation according to the "law of initial level" (Wilder, 1931). Wilder proposed that the higher is the initial level of the activity of the physiological system, the lower is the reaction of this system on the relevant task. However, in healthy subjects involved in a meaningful activity and highly motivated, autonomic variables may increase regardless of their initial level (O'Gorman \& Jamieson, 1977; Lovallo et al., 1986). Wilder's law seems to be relevant only for pathological anxiety. Thus, the low autonomic reaction in pathologically anxious persons may not relate to the high initial level by itself, but rather to the inability of the subject to accept the challenge of the task that requires search activity.

Sleep structure is also able to separate adaptive and maladaptive anxiety. We analyzed sleep change in 27 healthy students on a post-examination night in comparison to the post-holidays nights (Rotenberg \& Arshavsky, $1979 \mathrm{a}, \mathrm{b})$. Thirty minutes before the examination and thirty minutes after, we recorded their heart rate frequency, arterial blood pressure and bioelectrical activity of the orbicular muscles of the mouth. The control data on these indices were obtained on the one of the term days. Before the examination all subjects showed rise in autonomic variables and muscle tension compared with the control measures. However, after the examination, two groups could be separated. The Group I subjects (16 students) indices dropped to the control level, whereas the indices of subjects in the Group II remained at a stable high level. Students of Group II demonstrated a significant increase in REM sleep percentage on the post-examination night compared with the control night and with the post-examination night of the Group I subjects. The subjects of Group II showed worse results in resolving logical tasks on the evening after examination (before sleep) than on the following morning; also, their results were worse than those of Group I.

We have proposed a hypothesis that the subjects of Group I exhibited a normal emotional tension, which ensured psycho-physiological mobilization for overcoming the stressful situation and diminished when the situation passed. The subjects of Group II have displayed a maladaptive emotional tension. It did not diminish after the stressful situation was over and required REM sleep for its disappearance. An additional support for this approach comes from data demonstrating that slow post-stress catecholamine decline is accompanied by poor performance, neuroticism and pathological anxiety (Lader, 1983). 
Maladaptive anxiety determines paradoxical relationships between sleep disturbances and daytime alertness. Recently we investigated daytime wakefulness/sleepiness and night sleep structure in patients with sleep apnea and in patients with depression/anxiety (Kayumov et al., 2000). We have found that in patients with sleep apnea the ability to remain awake during soporofic circumstances measured by Maintenance of Wakefulness Test (MWT) correlated negatively with stage 1 sleep. The latter correlated negatively with the total sleep time and with slow wave sleep. It looks very natural: the more disturbed is the night sleep due to sleep apnea, the more difficult it is to maintain the daytime alertness. However, in patients with depression/anxiety MWT scores correlated negatively with total sleep time and slow wave sleep (stage 3), while Multiple Sleep Latency Test correlated negatively with total sleep time and sleep efficiency. It means, that the more disturbed is the night sleep, the less easy subject is able to go to sleep during the day. Maladaptive tension disturbs night sleep and at the same time prevents daytime sleep. It determines a very well known paradoxical combination of the subjective sleepiness (caused by night sleep disturbance) with high irritation and inability to sleep.

\section{PSYCHOSOMATIC DISORDERS}

According to the search activity concept, absence of search activity and especially renunciation of search in stressful conditions is the main predisposition to psychosomatic disorders. More and more facts show that the emergence and development of psychosomatic diseases, including ischemic heart disease, myocardial infarction, malignant tumors, duodenal ulcers etc. very frequently follow overt and covert depression (Engel \& Schmale, 1967; Glass \& Carver, 1980; Justice, 1986; Appels, 1979; Lyketsos et al., 1987). Symptoms of depression represent renunciation of search: passivity, lack of initiative, giving up in front of life challenges. On the other hand, both constructive aggression (creativity) and destructive aggression directed outward reduce the risk of psychosomatic diseases (Ammon et al., 1982). This stands in good agreement with data about the competitive relations between learned helplessness (depression) and aggressive behavior (Pittman \& Pittman, 1979; ), and with experimental data showing that aggressive behavior during stress prevents the development of somatic disturbances (Weiss, 1977). Individuals who withstand emotional stress very well and do not fall ill afterward exhibit clear aims and more constructive relations with the world. They are fighters with a pronounced motivation of achievement (Kobasa, 1979). At the same time a combination of stress with the blockade of active search behavior soon leads to the development of peptic ulcer (Kukleta, 1979).
We have investigated the development of giving up reaction and the psychological predisposition to it in healthy subjects and in patients with peptic ulcer and essential blood hypertension (Rotenberg \& Korosteleva, 1990). Subjects faced logical problems of varying difficulty, but their solution were never estimated by the experimenter as correct. The problems were numbered in the order in which they were offered. After the first attempts of subjects to stop efforts they were suggested to continue. We have studied the following behavioral characteristics:

The number of the test provoking the subject's first attempt to renounce his efforts, it means the beginning of the formation of giving-up reaction.

The total number of the tests needed to cause a final renounce in spite of the experimenter's inducement. It reflects resistance to the negative reinforcement.

Peptic ulcer patients were divided in two groups according to how soon they made the first attempts to renounce their efforts. Patients who showed an early first renunciation of efforts $(n=26)$ in contrast to patients who showed its late onset $(\mathrm{n}=14)$ displayed a combination of the prominent need to achieve success (according to Heckhausen variant of TAT) with a predominant negative forecast of the results of efforts. The predominance of the negative forecast of efforts outcome should block search behavior, and, combined with the need for success, may cause ambivalent attitudes to the task and the development of an unproductive emotional tension. This group of patients was characterized by the low tolerance to frustration (according to Rosenzweig, 1935), high fixation on the obstacles and high feeling of one's own guilt for failures. Such combination of motives determined an early development of renounce. The patients forming this group, as a rule, referred to a psychogenic cause of their disease or its exacerbation.

In control group as well as in patients the experience of giving up increased a special form of reaction on frustration - fixation on obstacles.

Patients showed a giving - up reaction sooner than healthy control subjects. At the same time they differed from the control in the dynamic of the fixation on obstacles. Patients displayed a high initial level of the fixation on obstacles however after all renunciations it increased relatively less than in healthy subjects. This may indicate that in patients the giving-up reaction is a customary form of behavior in everyday life and additional obstacles do not change this attitude dramatically. (In contrast to the control group of subjects, who in everyday life apparently display this reaction less frequently and it is more acute after unavoidable failures and giving-up reaction). Consequently, one can speak of a more stable and generalized renunciation of search in patients. Their inherent desire for success, due to the negative forecast of results and low level of tolerance to 
frustration is not realized in search activity and changes into unproductive health-ruining emotional tension.

In the group of patients with a late first renounce of the efforts this renounce nevertheless occurs substantially sooner than in the corresponding group of healthy subjects.

Patients with blood hypertension (15 persons), just as the peptic ulcer patients, made the first attempts to renounce their efforts much sooner than the healthy subjects. However, a total number of the tests needed to develop the giving-up reaction in these patients were almost equal to the normative group. In the course of frustration they showed a sharp rise in the reactions reflecting the desire to confess their guilt. Combined with a low level of the failure avoidance motive this data may suggest that patients with hypertension continued their efforts not because they were oriented to a search for ways to overcome the obstacle, but because they could not afford a socially disapproved action and to stop efforts. In these conditions efforts might bear a stereotyped character, and inability to stop the increase of inner tension.

This investigation is related to the previous investigation of the reaction to emotional and intellectual stress in 12 subjects suffering from the initial stage of essential hypertension (Rotenberg \& Alexeyev, 1981). Emotional stress was induced along the lines of the classical level-of-aspiration experiment suggested by K.Levin. Patients were also faced with intellectual tasks, and the discrimination of the level of aspiration was arbitrary carried out by the experimenter. The experiment was preceded and followed by polygraphic registration of the heart rate (HR), skin rheovasography, and measurements of arterial pressure. On the nights before and after the emotional stress, polysomnography was performed. The pre-stress control night was preceded by an adaptation night.

According to the reaction on stress, it was possible to divide patients in two groups. In Group I patients, emotional stress was followed by longer slow wave sleep (SWS), in Group II, by REM sleep. In both instances, stress led to a rise in arterial pressure, compared with baseline value. In Group I, however, this was due to a rise in the general peripheral vascular resistance with a relative drop in the cardiac output and the blood volume. In Group II, the rise in arterial pressure resulted from an expansion of the cardiac output accompanied by some drop of peripheral vascular resistance. It is highly relevant that the rise in arterial pressure was accompanied by a rise in cardiac volume only in Group II patients. The cardiac volume in Group I subjects did not display a significant post-stress change. On the poststress night, their SWS time became longer and their REM sleep decreased. Patients of the second group exhibited a longer REM sleep time, a shorter SWS time, and a negative REM-SWS correlation. A control group of 8 subjects, for whom the third night was registered without previous stress, did not exhibit sleep structure changes.

These two types of sleep change strikingly resemble two types of reactions of healthy students to examination stress. It is possible to suggest that an excessive rise in cardiac output in stress condition that does not require motor activity may be a feature of maladaptive emotional tension. A rise of arterial pressure determined by increased stroke volume and frequency of cardiac contractions combined with normal peripheral resistance corresponds to suppressed anxiety (Schors, 1970). Funkenstein et al. (1957) found that patients who showed the profound effect of metacholine on blood pressure expressed depression or anxiety, whereas patients who showed the smaller effect expressed interpersonal anger. Metacholine has more sustained effect on the increased cardiac output than on vasoconstriction. So blood pressure caused by cardiac output without a rise in general peripheral resistance is related more to depression (renunciation of search) and requires REM sleep for its compensation. A similar change in haemodynamic indices was detected in dogs exposed to an irregular administration of electric shocks (Anderson \& Jingling, 1978), a method of inducing learned helplessness. The dog's behavior exactly corresponded to this state being marked by freezing. It is possible to speculate that only this type of blood hypertension in humans reflects a real psychosomatic disorder, while the opposite one may reflect a particular type of normal mobilization in front of obstacles and tasks.

Search activity concept solves a paradox related to the ambiguous role of Type A behavior in the development of the coronary heart disease (Rotenberg, 1995). This type of behavior was considered to be a predisposition to the ischemic heart disease. On the first glance, it looks like a contradiction to the statements proposed by the search activity concept. A very strong orientation on goals and achievements, challenge seeking, time urgency, unlimited activity - all these symptoms are components of behavior that resemble search activity. According to the concept, this type of behavior has to protect subject from the psychosomatic disorders and in any case it cannot cause these disorders. However, further investigations (Williams, 1986) have shown that exactly these components of the Type A behavior are not related to the ischemic heart disease. Only suppressed hostility and anger based on the high competition, but not challenge seeking per se, correlate with coronary heart disease. According to Glass and Karver (1980), competitive Type A persons are extremely sensitive to their ability to control the environment. If they feel that they are unable to control the situation and to be the best in any competitive conditions, they suddenly renounce their efforts after a relatively short period of a very hard fight. This renunciation is even more promi- 
nent than in Type B. Hostility and anger suppression, like repression (see above) reflects renunciation of search because the corresponding behavior is blocked. Such renunciation can be especially harmful after a hard long-lasting activity. At the same time, other characteristics of Type A behavior like working hard and seeking challenge do not predispose subjects to coronary heart disease. For instance, Type A Japanese being not competitive and hostile do not demonstrate an increase in ischemic heart disease. Type A behavior without competition can have even a protective effect on heart. Thus, time urgency and emotional arousal are the inverse predictors of mortality in women with a premature acute myocardial infarction, while the relaxed Type B behavior characterized by the low time urgency increases the risk of death in these patients (Ragland \& Brand, 1988; Powell et all, 1993). The authors are speculating that the absence of time urgency may be a marker of depression, but it is more reasonable to suggest that it is a marker of the relatively low motivation in search activity.

Search activity concept helps also to explain non-linear relationships between psychosomatic and neurotic disorders. There are two opposite approaches to these relationships. According to one of them, autonomic and hormonal accompaniments of neurotic anxiety or neurotic depression correspond to the initial stage of the development of psychosomatic disorders. Autonomic dysregulation of inner organs and systems caused by emotional tension create the predisposition for organic body damage (Uexkull, 1979). This approach is based on clinical experience and can help to explain data about the relatively high risk of somatic diseases and death in neurotic patients (Eastwood \& Trelyn, 1972; Sims, 1973).

Another point of view, also based on clinical experience, puts neurotic and psychosomatic disorders on opposite pans: the more expressed are neurotic symptoms, the less are organic body disorders and vice versa (Krasnuschkin, 1942). I hypothesized that the main factor determining the course of psychosomatic disorders is the quality of the dominant neurotic syndrome. For instance, depression as a manifestation of the renunciation of search really belongs to the pathogenetic mechanisms of psychosomatic disorders, but hypochondria or hysterical conversion may even prevent the development of these diseases.

We have studied 311 patients with different somatic diseases (gastritis, duodenal ulcer, arterial hypertension, ischemic heart disease, pneumonia, and asthma bronchialis) (Rotenberg \& Schattenstein, 1990). All patients were examined with the MMPI Test. In order to study the connections between the psychic state and the course of the somatic disease we have selected groups of patients with different degrees of manifestation of the same somatic disorders. For example, we divided pa- tients with peptic ulcer into two groups, with and without Haudek's niche in the roentgenologic study. Patients with ischemic heart disease were divided into two groups, with and without past cardiac infarction.

Almost all patients with peptic ulcer but without Haudek's niche had different neurotic disorders, including predominating hypochondriasis. In patients with Haudek's niche, hypochondriasis was prominent much rare. The domination of the D (Depression) scale on MMPI corresponded to a profound niche, while the domination of Hs (Hypochondriasis) scale corresponded to the absence or to the very superficial defect of mucosa. Patients with ischemic heart disease who had a myocardial infarction in the past had symptom of hypochondria more often in comparison to patients without infarction. In almost all diseases considered to be psychosomatic in their nature it is a low correlation between the Hs and D scale. (Table 2) In somatic diseases being not considered as psychosomatic in its nature and in neurotic disorders the correlation between these two scales is high.

Table 2 Correlations between Hs and D MMPI Scales in patients with somatic disorders and healthy subjects.

\begin{tabular}{|l|c|c|c|}
\hline \multicolumn{1}{|c|}{ Diseases } & Number of patients & Correlatients & Significance \\
\hline Ischemic heart disease & 29 & 0,13 & $>.05$ \\
\hline Cholecystitis & 37 & 0.20 & $>.05$ \\
\hline Pancreatitis & 24 & 0.23 & $>.05$ \\
\hline Asthmatic bronchitis & 25 & 0.28 & $>.05$ \\
\hline Ulcer duodenum & 44 & 0.36 & $<.05$ \\
\hline Arterial hypertension & 31 & 0.39 & $<.05$ \\
\hline Asthma bronchialis & 40 & 0.52 & $<.01$ \\
\hline Healthy persons & 38 & 0.59 & $<.01$ \\
\hline Pneumonia & 32 & 0.66 & $<.01$ \\
\hline Gastritis & 24 & 0.78 & $<.01$ \\
\hline Nephritis & 25 & 0.81 & $<.01$ \\
\hline
\end{tabular}

Depression is a typical example of renunciation of search, thus its correlation with the expression of psychosomatic disorders is very logical. At the same time, hypochondria (fixation on somatic complains) opens a new opportunity for active behavior oriented exclusively towards health protection and restoration. In this state the subject is searching for the physician's support and for conditions in his life and activity that can secure his/her health. If search activity is oriented in this direction, nothing can stop it and renunciation of search is impossible, because it is no way to block subject's care about his/her health.

Moreover, real life difficulties can only intensify such a fixation on health problems and stimulate the corresponding hypochondriac behavior, especially if other forms of search behavior are blocked for some reasons. For body resistance, the precise direction of search activity is not significant because any search behavior, including those unacceptable for the society, has a pro- 
tective function for health and is very welcome from the biological point of view.

Thus, according to the search activity concept, the development of psychosomatic disease can be presented in a following scheme. The main general pathogenetic factor is renunciation of search, which can display itself as overt or covert depression or as "given up- giving up" complex (Engel \& Schmale, 1967). However, overt depressive and anxious behavior and somatic complaints are unacceptable for the person with psychological predispositions to psychosomatic diseases.

Depression and anxiety, as other forms of neurotic behavior, are intolerable to the subject and are repressed. The subject is not aware of his own mood. MMPI scale $\mathrm{D}$, even though most prominent, is usually not as high as in patients with clinical depression.

A combination of renunciation of search with the inability to recognize this state is a basis for the consequent psychosomatic disorders. Together with alexithymia it is a reason why psychosomatic disorders sometimes start suddenly without any preliminary signals and immediately develop into a severe form, as in the cases of penetrated ulcer or myocardial infarction.

However, when the disease has already appeared it sometimes causes changes in personal attitudes, and as a result, hypochodriacal complaints arise. These complaints determine new orientation of the active behavior. That is why hypochondriasis is prognostically favorable.

If the patient continues to repress from consciousness all manifestations of the disease and tries further to ignore his own sensation, it may create a prominent risk for his health. For instance, in most patients myocardiac infarction provokes hypochondriacal complaints and helps to change attitudes and recover search activity, which is now oriented toward the accessible goal of health restoration. The minority of patients who cannot change their attitudes might belong to the dangerous group that has a chance of repeating the myocardial infarction.

The practical outcome of this explanation is that it is not reasonable and even dangerous to suppress hypochodriac symptoms of psychosomatic patients using neuroleptics without finding a new appropriate opportunity for their search behavior. Neuroleptics further decrease search activity and may cause the exacerbation of psychosomatic symptoms.

The search activity concept helps to explain why animals in the condition of learned helplessness display a combination of depressive-like behavior with somatic disturbances and can die very soon whereas people usually suffer from psychosomatic disturbances for many years, often even without the appropriate treatment. It is a consequence of the defense system with a negative feedback which belongs exclusively to humans. Due to this system the disease itself stimulates the appearance of hypochondriacal behavior, which diminishes the severity of the disease.

For the somatic diseases that do not belong to the psychosomatic group, depression and hypochondria are not so important because they play neither major pathogenic nor substantial sanogenic role. In these kind of somatic diseases, they only accompany the disease and reflect the psychological reaction on the disease. For instance, although search activity is very important for immune system, the development of the infectious disease requires also infection by itself. That is why depression and hypochondria can appear in these cases simultaneously. Only in psychosomatic diseases depression is a crucial pathogenic and hypochondria a crucial sanogenic factors.

In conclusion, let us discuss some relations among hypochondria, masked depression, overt depression, and psychosomatic disorders. Masked depression covered by somatic complaints can help the subject to explain himself, through these complaints, elusive nature of his disability; but unlike hypochondria, these complaints do not stimulate subject toward the reorientation of his behavior, and patients usually do not increase their search activity. They do not fight for health restoration, they do not build flexible systems for health protection. Depression by itself, although masked, does not allow such active behavior. Masked depression is a result of the unacceptability of a depressive mood for the subject's own consciousness. But unlike a psychosomatic predisposition, in masked depression as in overt depression, the subject does not ignore his negative body feelings. Moreover, these feelings are even increased. Of course, masked depression does not save the subject from psychosomatic disease, but a low threshold for body sensations helps the subject to pay attention to the somatic state, and therefore he has more of a chance to receive medical help.

\section{ANOREXIA NERVOSA- A MISDIRECTED SEARCH ACTIVITY}

According to the literary data (see critical review, Rotenberg, 2000), a moderate distortion of the perception of body size and weight, even if present, is not enough to explain the extreme anorectic behavior. Depression often, although not always, precedes the onset of anorexia nervosa (Deep et al., 1995), and the clinical picture of anorexia nervosa contains some depressive features like low mood, sleep disturbances (Benca et al.,1992), inward hostility (Tiller et al., 1995), reduced motivations (Wiederman et al., 1996). However, many important clinical features of anorexia nervosa do not correspond to those of depression. Appetite in anorectic patients is not decreased, and patients are continuously struggling with their strong desire for food. Goaldirected activity is not blocked, and patients often display sly and complicated behavioral habits in their 
struggle with relatives and doctors whilst attempting to avoid food. In contrast to depressed adolescents, anorectics often demonstrate good academic performance (Toro et al., 1995). Finally, antidepressant drugs sometimes have a worsening effect on the disorder (Brambilla, 1997).

Thus, although anorexia nervosa has some features in common with depression, it cannot be explained only by depression. Another theoretical paradigm has to be invoked. The concept of helplessness seems to be a good candidate for this paradigm. Childhood helplessness is often present in these patients (Troop \& Treasure, 1997), and there are many predispositions to the development of helplessness (see Rotenberg, 2000). An important predisposition to helplessness is the inability to control life events, and according to Slade (1982) the central factor in the development of anorexia is a perceived lack of control over any important aspects of life (relationships with peers, parents, desired achievements etc.) The less this control, the higher the frustration, which results in a great desire for control at least in one domain. Thus, anorexia is an attempt to compensate for lack of primary natural control over life events by an artificial secondary control over eating behavior. In this context, a breakdown of anorectic behavior produces a terror of loosing control, this being a reason why it is so difficult to treat anorexia. According to this model, reducing control should result in greater body image distortion, stimulating patients to increase their anorectic behavior.

However, the concentration on keeping control is a weak point of the all theory. First of all, the inability to keep control is an important, but not the sole, and even not the main, predisposition to learned helplessness. As we have already stressed, the complete control achieved without efforts does not "immunize" subject to learned helplessness (Jones et al., 1977). On the contrary, even unsuccessful but continuous efforts in a situation that makes real control impossible preserve the subject from learned helplessness (Brosschot et al., 1992). This suggests that efforts to achieve control (search activity as a process) may be more important than the control itself. (This conclusion is in a good agreement with the recent data (Eriksen \& Ursin, 1999) that approaching difficult situations and considering problems as challenges have more positive impact on subjective health than keeping control in the work situation.)

On the other hand, it is difficult to argue about keeping control over eating behavior in patients with anorexia. For instance, drugs that reduce appetite should be helpful in keeping such control, but they are rarely used by patients perhaps because they decrease efforts to keep control. Real control is based on the feedback between behavior and goal achievement, and makes behavior flexible; the behavior of anorectic patients is not flexible. It is more reasonable to suggest that the behavior of these patients is controlled by the anorexia than to suggest that the patients are keeping control over their eating behavior. The patient is for some reason motivated not to eat, and this motivation is out of control. But what is beyond this motivation? Helplessness, as mentioned above, displays a particular form of renunciation of search, a state of giving up in the face of challenges. Anorectic patients display helplessness in different domains of life, before developing anorectic behavior. In this context, the ability to refuse food in the face of strong and stable challenges (challenge of appetite, challenge of the requirements of relatives and doctors) displays a continuous effort, and a particular search activity, which compensate for the lack of search activity in other domains. Anorectic behavior is a process of struggling with challenges. It is not a phobia of eating, of weight increase or even a phobia of losing control but a phobia of giving up in the face of challenges. Distortion of body image is secondary to this challenge and is a rationalization of active anorectic behavior. Until the subject continues this behavior, he/she is at least partly overcoming renunciation of search.

This suggestion is supported by some recent investigations. One experimental study examined the effects of actual and perceived control on body image distortion in anorexia (Waller \& Hodgson, 1996). The authors used anagrams as intellectual tasks. The task performance of healthy and anorectic women was affected by the actual difficulty of the tasks, and there was no effect of perceived controllability on the number of anagrams solved. At the same time, women with eating disorders overestimated their body size when carrying out an objectively easy task that they perceived as a difficult one, while healthy controls overestimated their body size when they were performing a difficult task that they perceived as such. When the task is easy but it is suggested that it is difficult, a person must have a feeling of high controllability because, as mentioned above, the ability to solve the task depends on the real difficulty of the task. However, this feeling of high controllability does not improve body image. Moreover, patients even overestimate body size, since the level of challenge in this situation was less than was expected, and efforts (search activity) were under-used. On the other hand, the suggestion of low controllability because of the difficult task had no effect on body size estimation because the expectation of challenge corresponds to the real challenge. Thus, challenge is more important than the level of control.

Bulimia nervosa $(\mathrm{BN})$ is considered in literature to be another type of eating disorders comparable to anorexia nervosa (AN). However, I suggest that these two types of eating disorders are different and even opposite one to another according to their psychological and behavioral background. While AN represents search activity (peculiar, restricted and misdirected), BN represents an 
opposite state - repetitive giving up with lack of control and impulsivity, often combined with depression. While in anorexia every rejection of food is estimated by the patient as her victory, in bulimia every episode of overeating is estimated by the patient as a defeat.

This suggestion was confirmed in the recent investigation performed in collaboration with D. Stein et al. from the Tel-Hashomer Hospital (in press). Investigators have compared 3 groups of girls: healthy control, AN and $\mathrm{BN}$ patients. Investigation of clinical and psychological variables including test BASE was performed before and after treatment. Before treatment girls with $\mathrm{BN}$ rejected the passive behavioral strategy (renunciation of search) significantly less than girls in two other groups. The structure of behavioral attitudes was different in clinical groups in comparison to the control group. In the control group dominated search activity while in both clinical groups dominated chaotic behavior. Only girls with BN rejected stereotyped behavior (this adaptive goal-oriented behavior had in this group a negative meaning, although, as we have stressed before, in girls it often dominates). According to some psychological variables $\mathrm{AN}$ group was more close than $\mathrm{BN}$ group to the control group and was not different from the control group according to BASE scales. Eating disorder characteristics were related to problem-solving behavioral ineffectiveness (passive plus chaotic behavior) only in girls with $\mathrm{BN}$.

In the process of treatment, only girls with $\mathrm{BN}$ demonstrated a normalization of the BASE structure (increase of search activity and decrease of passive and chaotic behavior). In AN the structure of behavioral attitudes remained stable after the treatment, and it confirms my conclusion that the structure of behavioral attitudes in $\mathrm{AN}$ is initially more normal than in $\mathrm{BN}$ and for this reason less sensitive to the treatment. The normalization of behavioral attitudes in $\mathrm{BN}$ appeared in parallel with the decrease of depression anxiety and eating disorders.

This theoretical approach determines a possible therapeutic strategy in anorexia nervosa. It is necessary to collaborate with the patient to discover those domains in her life where she is still able to start search activity, and to increase her self-esteem in order to produce this search activity. Even small initial achievements in any area may increase the subject's feeling that it is possible to confront challenges, not only in the domain of eating behavior. According to our own initial clinical experience, even explaining this mechanism, together with the psychotherapeutic restoration of self-confidence (by using episodes of previous achievements, etc.) and the stimulation toward moderate challenges, have a positive outcome on the disorder.

\section{PSYCHOSIS AND SEARCH ACTIVITY}

According to the well known monoamine conception of schizophrenia (Gray et al., 1991; Swerdlow \& Koob,
1987) the appearance of the positive symptoms is related to the hyperactivity of brain catecholamine systems ( mainly dopamine), and the beneficial effect of neuroleptics in reducing positive symptoms is based on the blocking of dopamine receptors of the limbic system of the brain. Parkinsonian-like disorders caused by traditional neuroleptics are considered to be a side effect of the impairment of brain dopamine activity. By taking into consideration these data, it is possible to suggest that positive symptoms may represent an intensive but irregular and misdirected search activity (Rotenberg, 1994) as it happens when search activity is totally determined by DA (see about brain CA in REM) . The following reasons suggest that positive symptoms are representative of misdirected search activity:

Paranoid behavior and hallucinations are examples of search activity: both are active behaviors without definite promise of results. A subject never can be sure about future events in his artificial world or about outcomes of his own interaction with this world. At the same time, the subject remains highly sensitive to all events and outcomes, which also is consistent with the definition of search activity. A study (McGuire et al., 1996) showed that auditory hallucinations are associated with increased metabolic activity of brain centers for inner speech, i.e., that represent active verbalization. Aggravation of psychotic symptoms is accompanied by a reduction of REM sleep requirement: REM sleep is reduced without a subsequent rebound effect (Mendelson et al., 1977); the relative increase of psychotic symptoms after neuroleptic withdrawal correlates negatively with REM\% and eye movement (EM) density (Neylan et al., 1992). It means that REM sleep pressure and REM sleep requirement are decreased. EM density in the 1 st and 3rd cycles is significantly lower in schizophrenic patients with the relative increase of positive symptoms in comparison to patients with the domination of negative symptoms (Rotenberg et al., 1997c). On the other hand, neuroleptic treatment leads to an increase in REM sleep. Being neuroleptic-free, patients demonstrate a decrease of REM sleep in parallel with the increase of positive symptoms (Nofzinger et al., 1993).

Schizophrenic patients with positive symptoms display an exaggerated orienting reaction (Kim et al., 1993) and a "first night effect" (Rotenberg et al., 1998) as a particular orienting reaction to a new environment. This orienting reaction includes search activity, and may be based on a relative higher response of the brain monoamine system, in comparison to patients with negative symptoms (Wolkin et al., 1996). At the same time, schizophrenic patients with the domination of negative symptoms demonstrate a failure of such response to the environment (Frith, 1992).

The consideration of positive symptoms as the manifestation of misdirected search activity is leading to the 
assumption that positive symptoms might protect patients with schizophrenia from somatic and psychosomatic disorders. However, literary data related to this topic are contradictive. On the one hand, it was shown that older patients with schizophrenia had significantly lower physical co-morbidity compared to patients with major depression (Lacro, Jeste, 1994; Adams \& Ball, 2000); older schizophrenia patients report even fewer co-morbid physical illnesses than healthy comparison subjects (Jeste et al., 1996). Of course, it can be only a sign of the decreased attention to the physical symptoms, because illnesses in schizophrenic patients, if present, tend to be more severe (Jeste et al., 1996). However, it was shown (Goldman, 1999) that patients with schizophrenia are at decreased risk for certain disorders, such as rheumatoid arthritis and allergies. On the other hand, some investigators found that epilepsy, inflammatory diseases of the bowel and some other somatic disorders were over-represented in schizophrenia when compared with people without psychiatric disorders (Makikyro et al., 1998; Dalmao et al., 1998). It is worth to emphasize, that according to the review (Goldman, 1999) cerebrovascular disease, allergies, osteoarthritis, gallbladder disease, menstrual disorders have all been reported to occur less often in patients with schizophrenia compared with the general population. Most of these diseases have a psychosomatic component in their pathogenesis. On the other hand, the general medical problems schizophrenic patients are predisposed to are either complications of the psychotic disorders itself, or substance-abuse, or those related to patients socioeconomic status like poor nutrition and homelessness. The greatest number of excess deaths in schizophrenia is due to respiratory diseases (Joukamaa et al., 2001). It is also necessary to take into consideration that investigators usually do not compare somatic disorders in patients with and without dominating positive symptoms. Secondly, most patients are on the neuroleptic treatment, and the latter, suppressing positive symptoms together with all other forms of search activity may predispose patients to somatic disorders. Thus, this problem requires a more precise investigation.

According to the search activity concept, brain CA hyperactivity being a main biological marker of positive schizophrenic symptoms is not to be understood as a cause of psychotic symptoms but rather as a correlate of intensive search activity. Neuroleptics reduce search activity and remove positive symptoms. In our investigation (Rotenberg \& Arshavsky, 1979a), we established that the artificial extrapyramidal syndrome caused by neuroleptics is more prominent and appears more rapidly in a state of freezing. Active avoidance or selfstimulation of the lateral hypothalamic nucleus, led to reduction and delay of this neuroleptic syndrome. Thus, neuroleptics may produce the general predisposition for the development of the neuroleptic syndrome by block- ing brain CA receptors and, consequently, by blocking search activity. That's why the restoration of search activity can prevent the development of this syndrome. It may also explain the "paradoxical kinesia" in the Parkinson-like disorders in the face of sudden activating events.

There are some contradictions in the relationship between positive symptoms, catecholaminergic hyperactivity and latent inhibition: latent inhibition correlates better with dopaminergic hyperactivity and with the acuteness of the disease than with positive symptoms (Gray, 1991). This contradiction can be resolved by assuming that "true" positive symptoms include only irregular search activity, while stereotyped delusions and hallucinations in chronic patients do not belong to this description and do not correlate (negatively) with latent inhibition.

Recently, search activity concept was creatively used for an integrative approach to suicidal behavior (Weinberg, 2000). According to this approach, suicidal tendencies and suicidal act express different processes: while renunciation of search increases suicidal tendencies, the suicidal attempt itself expresses misdirected search activity. Author suggests, that under the burden of unbearable mental pain the person, who has renounced much of his/her search activity, displaces the remnants of search activity into the performance of suicidal act.

\section{CONCLUSION}

Search activity concept presents a new classification of behavior and provides a new approach to the relationships between behavior, stress, body resistance, REM sleep functions, memory consolidation and brain monoamine activity.

The application of this concept to the medicine opens a new perspective in reconsideration of mechanisms and treatment of mental and psychosomatic disorders. The present publication is only the first step toward a creation of an integrative, holistic and polydimensional theory presumably able to avoid many contradictions in modern physiology, psychology and medicine. However, for this reason all aspects of this theory are open for a serious and substantial discussion.

\section{REFERENCES}

Abramson, L.Y., Seligman, M.E.P., \& Teasdale, J. (1978). Learned helplessness in humans: Critique and reformulation. Journal of Abnormal Psychology, 87, 32-48.

Adrien, J., Dugovic, Ch., \& Martin, P. (1991). Sleepwakefulness patterns in the helpless rat. Physiology and Behavior, 49, 257-262.

Ammon, G., Ammon, G., \& Griepenstroh, D. (1982). Behandlungsmethodik und Widerstand von der traditionellen Psychoanalyse zur dynamischen Psychiatrie. In: G.Ammon (Ed.) 
Hanbuch der Dynamischen Psychiatrie. Munich und Basel: Ernst Reinhardt Verlag, 351-406.

Anderson, D.E, \& Jingling, J.E. (1978). Total peripheral resistance changes in dogs during aversive classical conditioning. The Pavlovian Journal of Biological Science, 13, 241-246.

Anisman H., Zacharko R.M. (1982) Depression: the predisposing influence of stress. The Behavioral and Brain Sciences, 5: 89-138.

Appels, A. (1979). Myocardial infarction and depression. A cross-validation of Dreyfus findings. Activitas Nervosa Superior (Praha), 21, 65-66.

Armitage, R., Rochlen, A., Fitch, Th., Trivedi, M., \& Rush, J. (1995). Dream recall and major depression: A preliminary report. Dreaming, 5, 189-198.

Arshavsky, V.V., \& Rotenberg, V.S. (1976). Search activity and its influence on experimental and clinical pathology. Zhurnal Vysshey Nervnoy Deyatelnosti, 26, 424-428.

Barak, Y., Aizenberg, D., Szor, H., Swartz, M., Maor, R., \& Knobler, H.Y. (2005). Increased risk of attempted suicide among aging holocaust survivors. American Journal of Geriatric Psychiatry, 13, 701-704.

Benca, R.M., Obermeyer, W.H., Thisted, R.A., \& Gillin, J.C. (1992). Sleep and psychiatric disorders: a meta-analysis. Archives of General Psychiatry, 49, 651-668.

Berger, M., Riemann, D., \& Lauer, C. (1988). The effects of presleep stress on subsequent sleep EEG and dreams in healthy subjects and depressed patients. Sleep'86, Stuttgart and New York: Gustav Fischer Verlag, 84-86.

Blagrove, M. (2000). Dreams have meaning but no function. Behavioral and Brain Sciences, 23, 910-911.

Blier, P., Szabo, S.T., Haddjeri, N., Dong, J. (2000). Properties of noradrenergic neurons. International Journal of Neuropsychopharmacology, 3, (Suppl. 1) 36.

Brambilla, F. (1997). Neurotransmitter and neuroendocrine dysfunctions in anorexia nervosa: Do they have clincal significance? In Abstracts of the 14th World Congress on Psychosomatic Medicine, Cairns, Australia.

Brosschot, J., Benshop, R.J., Godaert, G.L.R., De Smet, M.B.M., Olff, M., Heijnen, C., Ballieux R.E. (1992). Effects of experimental psychological stress on distribution and function of peripheral blood cells. Psychosomatic Medicine, 54, 394-406.

Brunello, N. (2000). Noradrenaline involvement in antidepressant action. The International Journal of Neuropsychopharmacology, 3 (Suppl. 1) 29.

Cartwright, R., Luten, A., Young, M., Mercer, P., \& Bears, M. (1998a). Role of REM sleep and dream affect in overnight mood regulation: A study of normal volunteers. Psychiatry Research, 81, 1-8.

Cartwright, R., Young, M., Mercer, P., \& Bears, M. (1998b). Role of REM sleep and dream variables in the prediction of remission from depression. Psychiatry Research, 80, 249-255. Cespuglio, R., Bonnet, Ch., \& Marinesco, S. (1999). Sleep promoting influence of stress: Phenomenology and mechanisms. In: Abstracts of the 3rd International Congress of WFSRS, Dresden, 749.

Cloninger, C.R. (1986). A unified biosocial theory of personality and its role in the development of anxiety states. Psychiatry of Development, 3, 167-226.
Cloninger, C.R. (1987). A systematic method for clinical description and classification of personality variants. Archives of General Psychiatry, 44, 573-588.

Coenen, A.M.L., \& van Luijtelaar, E.L.J.M. (1997). Effects of benzodiazepines, sleep and sleep deprivation on vigilance and memory. Acta Neurologia Belgia, 97, 123-129.

Cohen, D. (1974). Effect of personality and presleep mood on dream recall. Journal of Abnormal Psychology, 83, 151-156.

Cohen D. (1979) Sleep and dreaming. Origins, Nature and Functions. Oxford, Pergamon Press.

Cohen H., Edelman, A., Bowen, R., \& Delmont, W. (1975). Sleep and self-stimulation in the rat. In: Abstracts of the 11 Annual Meeting of APSS, New York, 75.

Conduit, R., Crewther, S.G., \& Coleman, G. (2000). Shedding old assumptions and consolidating what we know: Toward an attention-based model of dreaming. Behavioral and Brain Sciences, 23, 924-928.

Conway, J., \& Smith, C. (1994). REM sleep and learning in humans : A sensitivity to specific types of learning tasks. Abstracts of the 12th Congress of the European Sleep Research Society, Florence.

Current Research on Sleep and Dreams (1966). Public Health Service Publication, N 1389.

Dalmau, A.B., Bergman B.K., \& Brismar B.G. (1998). Somatic morbidity among patients diagnosed with affective psychoses and paranoid disorders. A case-control study. Psychosomatics, 39, 253-262.

De Boer, S.F., De Beun, R., Slangen, J.L., \& van der Gugten, J. (1990). Dynamics of plasma catecholamine and corticosterone concentrations during reinforced and extinguished operant behavior in rats. Physiology and Behavior, 47, 691-698.

Deep, A.L., Nagy, L.M., \& Weltzin, T.E. (1995). Premorbid onset of psychopathology in long term recovered anorexia nervosa. International Journal of Eating Disorders, 17, 291297.

Dienstbier, R.A. (1989). Arousal and physiological toughness: Implications for mental and physical health. Psychological Review, 96, 93-104.

Dohrenwend, B.P., Shrout, P.E., Egri, G., \& Mendelsohn, F.S. (1980). Nonspecific psychological distress and other dimensions of psychopathology: Measures for use in the general population. Arch. Gener. Psychiatry, 37: 1229-1236.

Domhoff, G.W. (2000). Needed: A new theory. Behavioral and Brain Sciences, 23, 928-930.

Eastwood, M.R., \& Trevalyn, M.H. (1972) Relationship betweeen physical and psychiatric disorder. Psychological Medicine, 2: 363-372.

Engel, G., \& Schmale, A. (1967). Psychoanalytic theory of somatic disorders. Journal of American Psychoanalytic Association, 15, 344-365.

Eriksen, H.R. \& Ursin, H. (1999). Subjective health complaints: is coping more important than control? Work and Stress, 13, 238-252.

Everson, C.A. (1995). Functional consequences of sustained sleep deprivation in the rat. Behavioral and Brain Research, 69, 43-54.

Fishbein, W. (2000). The case against memory consolidation in REM sleep: Balderdash! Behavioral and Brain Sciences, 23, 934-936. 
Fishbein, W., Kastaniotis C., \& Chattman, I. (1974). Paradoxical sleep: Prolonged augmentation following learning. Brain Research, 79, 61-75.

Folkman, S., \& Lazarus, R.S. (1988). Ways of coping questionnaire. Palo Alto, CA: Mind Garden.

Forsman, L., \& Johnson, M. (1993). An experimental and questionnaire study of self-esteem and competence strivings. Paper presented on the III European Congress of Psychology, Tampera.

Foulkes, D., \& Pivik, T. (1966). Dream deprivation. Effects on dream content. Science, 153: 1282-1284.

Frith C.D. (1992). The cognitive neuropsychology of schizophrenia. Hove, UK: Lawrence Elbraum Ass.

Funkenstein, D.H., King, S.H., \& Dorlette, M. (1957). Mastery of stress. Cambridge, MA: Harvard University Press.

Gaillard, J.-M. (1979). Brain catecholaminergic activity in relation to sleep. In: R.G.Priest, A. Pletsscher, J. Ward (Eds.) Sleep research. Proceedings of the Northern European Symposium on sleep research. Basle, September 26/27, 1978; 3541.

Gaillard, J.M. (1985). Involvement of noradrenaline in wakefulness and paradoxical sleep. In: A. Waquier, J.-M. Gaillard, J.M.Monti and M.Radulovacki (Eds.) Sleep: Neurotransmitters and Neuromodulators, New York: Raven Press, 57-67.

Gal, R., \& Lazarus, R.S. (1975). The role of activity in anticipating and confronting stressful situations. Journal of Human Stress , 1, 4-20.

Giuditta, A., Ambrosini, M.V., Montagnese, P., Mandile, P., Cotugno, M., Zucconi, G. G., Vescia S. (1995). The sequential hypothesis of the function of sleep. Behavioral and Brain Research, $69: 157-166$.

Glass, D., \& Carver, C. (1980). Helplessness and the coronary prone personality. In: J.Garber, M. Seligman (Eds.) Human Helplessness, Theory and Applications. New York and London: Academic Press, 223-244.

Goesling, W.J., Buchholz, A.R., \& Carreira, C.J. (1974). Conditioned immobility and ulcer development in rats. Journal of General Psychology, 91, 231-236.

Golbin, A.Z. (1979). Pathological sleep in children (in Russian) Leningrad: Medicina Publisher.

Goldman, L.S. (1999). Medical illness in patients with schizophrenia. Journal of Clinical Psychiatry, 60 suppl. 21 10-15 Gottesmann, C. (2002). The neurochemistry of waking and sleeping mental activity: The disinhibition-dopamine hypothesis. Psychiatry and Clinical Neurosciences, 56, 345-354.

Grastyan, E. (1976). Motivation and reinforcement. Acta Physiologica Academiae Scientiarum Hungaricae, 48, 299322.

Gray, J. (1982). The neuropsychology of anxiety: An inquiry into the functions of the septohippocampal system. Oxford: Oxford University Press.

Gray, J.A., Feldon, J., Rawlins, J.N.P., Hemsley, D.R., Smith, A.D. (1991). The neuropsychology of schizophrenia. The Behavioral and Brain Sciences, 14, 1-64.

Greenberg, R. (1977). On understanding sleep disorders and their psychopathology. McLean Hospital Journal, II, 3, 139146.

Greenberg, R., Fingar, R., Kantrowitz, J., \& Kawlich, S. (1970). The effects of REM deprivation: Implications for a theory of the psychological function of dreaming. British Journal of Medical Psychology, 43, 1-11.
Greenberg, R., Katz, H., Schwartz, W., \& Pearlman, C. (1992). A research-based reconsideration of the psychoanalytic theory of dreaming. Journal of American Psychoanalytic Association, 40, 531-550.

Grieser, C., Greenberg R., \& Harrison, R. (1972). The adaptive function of sleep: Differential effects of sleep on dreaming and recall. Journal of Abnormal Psychology, 80, 280-286. Hall, C.S. \& Van de Castle, R.I. (1966). The content analysis of dreams. Appleton-Century-Crofts/Meredith.

Hartmann, E. (1973). Functions of sleep. In: U.Jovanovic (Ed.) Nature of sleep. Stuttgart, Fischer Verlag, 238-252.

Hawkins, J., Phillips, N., Moore, J., Gilliland, M., Dunbar, S., \& Hicks, R. (1980). Emotionality and REMD: A rat swimming model. Physiology and Behavior, 25, 167-171.

Hobson, J.A., Pace-Schott, E.E., \& Stickgold, R. (2000) Dreaming and the brain: Toward a cognitive neuroscience of conscious states. Behavioral and Brain Sciences, 23, 793-843. Hong, Ch., Potkin, S.G., Antrobus, J.S., Dow, B.M., Callaghan, G.M., \& Gillin, J.Ch. (1997). REM sleep eye movement counts correlate with visual imagery in dreaming: A pilot study. Psychophysiology, 14, 377-381.

Indursky, P., \& Rotenberg, V.S. (1998). Change of mood during sleep and REM sleep variables. International Journal of Psychiatry in Clinical Practice, 2, 47-51.

Jeste, D.V., Gladsio, J.A., Lindamer, L.A., Lacro, J.P. (1996). Medical comorbidity in schizophrenia. Schizophrenia Bulletin, 22, 413-430.

Jones, S.L., Nation, J.R., \& Massad, P. (1977). Immunization against learned helplessness in man. Journal of Abnormal Psychology, 86, 75-83.

Joukamaa, M., Heliovaara, M., Knekt, P., Aromaa, A., Raitasalo, R., \& Lentinen, V. (2001) Mental disorders and causespecific mortality. British Journal of Psychiatry, 179, 498502.

Jouvet, M. (1965). Behavioral and EEG effects of paradoxical sleep deprivation in the cat. In: Proceedings of the 23rd International Congress of Physiological Science, Tokyo, 344-353. Jouvet M., \& Delorme J. (1965). Locus coeruleus et sommeil paradoxical. Current Research of Social Biology (Paris), 159, 895-899.

Justice, B. (1986). Evidence of psychosocial influence in disease onset. The Cancer Bulletin, 38, 241-244.

Kafi S., Bouras C., Constantinidis J., Gaillard J.-M. (1977) Paradoxical sleep and brain catecholamines in the rat after single and repeated administration of alpha-methylparathyrosine. Brain Research, 135: 123-134.

Kahan, T.L. (2000). The "problem" of dreaming in NREM sleep continuous to challenge reductionist (two generator) models of dream generation. Behavioral and Brain Sciences, 23, 956-958.

Kayumov, L., Rotenberg, V., Buttoo, K., Auch, Ch., PandiPerumal, S.R., \& Shapiro, C.M. (2000). Interrelationships between nocturnal sleep, daytime alertness, and sleepiness: Two types of alertness proposed. The Journal of Neuropsychiatry and Clinical Neurosciences, 12, 86-90.

Kim, D.K., Shin, Y.M., Kim, Ch.E., Cho, H.S., \& Kim Y.S. (1993). Electrodermal responsiveness, clinical variables and brain imaging in male chronic schizophrenics. Biological Psychiatry, 33, 786-793.

Knight, R.T. (1996). Contribution of human hippocampal region to novelty detection. Nature, 383, 256-259. 
Kobasa, S. (1979). Stressful life events, personality and health. An Inquiry into hardiness. Journal of Personality and Social Psychology, 37, 1-11.

Kolucy, R.S., Hartmann, M., Brown, D.G., \& Crisp, A.H. (1976). Sleep research and psychosomatic hypothesis. Postgraduate Medical Journal, 52, 53-56.

Korosteleva, I.S., \& Rotenberg, V.S. (1990) Psychologic predispositions and the consequences of the renunciation of search in normal subjects and in psychosomatic patients. Psychological Journal, 4, 84-90.

Kovalzon V.M. (1976) Evolutionary and ecological aspects of sleep. Uspekhi Sovremennoy Biologii, 83: 379-396.

Kovalzon, V.M., \& Tsibulski, V.L. (1984). REM sleep deprivation, stress and emotional behavior in rats. Behaviour and Brain Research, 14: 235-245.

Kramer, M. (1970). Manifest dream content in normal and psychopathological states. Archives of General Psychiatry, 22, 149-159.

Kramer, M. (1993). The selective mood regulatory function of dreaming: An update and revision. In: A. Moffitt, M. Kramer, R. Hoffmann (Eds.) The Functions of Dreaming. New York, Albany: State University of New York Press, 139-196.

Kramis, R.C., \& Routtenberg A. (1977). Dissociation of hippocampal EEG from its behavioral correlates by septal and hippocampal electrical stimulation. Brain Research, 125, 3749.

Kuiken, D., \& Sikora, S. (1993). The impact of dreams on waking thoughts and feelings. In: A. Moffitt, M. Kramer, R. Hoffmann (Eds.) The Function of Dreaming, State University of New York Press, 419-476.

Kukleta, M. (1979). System of behavioral inhibition in a stress situation: Possible role in neurosis. Activitas Nervosa Superior (Praha), 21, 32-33.

LaBerge, S. (2000). Lucid dreaming: Evidence and methodology. Behavioral and Brain Sciences, 23, 962-964.

Lacro, J.P., \& Jeste, D.V. (1994) Physical comorbidity and polypharmacy in older psychiatric patients. Biological Psychiatry, 36, 146-152.

Lader, M. (1975). The psychophysiology of mental illness. London and Boston: Routledge \& Keyan Paul.

Lader, M. (1979). The orienting reflex in anxiety and schizophrenia. In: H.D. Kimmel, E.H. van Olst, J.F. Orlebeke (Eds.) The orienting reflex in humans. Hillsdale, New York: Erlbaum , 607-617.

Lader, M. (1983). Anxiety and depression. In: A. Gale \& J.A.Edwards (Eds.) Physiological correlates of human behavior. Vol. III. Individual differences and psychopathology. London: Academic Press, 155-167.

Laudenslager, M.L., Ryan, S.M., Drugan, R.C., Hyson, R.L., $\&$ Maier, S.F. (1983). Coping and immunosuppression: Inescapable but not escapable shock suppresses lymphocute proliferation. Science, 221, 568-570.

Leconte, P., Hennevin, E., \& Block, V. (1973). Analyse des effects d'un apprentissage et de son niveau d'acquisition sur le sommeil paradoxal consecutif. Brain Research, 49, 367-379.

Lens, W., \& De Volder, M. (1980). Achievement motivation and intelligence test scores: A test of the Yerkes-Dodson hypothesis. Psychology of Belgia, 20, 49-59.

Levine S., \& Ursin H. (1991). What is stress? In: M.Brown, G. Koob, C. Rivier (Eds.) Stress, Neurobiology and Neuroen- docrinology, New York, Basel, Hong Kong, Marcel Dekker Inc. Pp. 5-21.

Liu, D., Diorio, J., Day, J.C., Francis, D.D., \& Meaney, M.J. (2000). Maternal care, hippocampal synaptogenesis and cognitive development in rats. Nature Neuroscience, 3, 799-806. Lovallo, W.R., Pincomb, G.A., \& Wilson, M.F. (1986). Predicting response to a reaction time task. Heart rate reactivity compared with Type A behavior. Psychophysiology, 23, 648656.

Lyketsos, C.G., Lyketsos, G.C., Richardson, S.C., \& Beis, A. (1987). Dysthymic states and depressive syndromes in physical conditions of presumably psychogenic origin. Acta Psychiatrica Scandinavia, 76, 529-534.

Makikyro, T., Karvonen, J.T., Hakko, H., Nieminen, P., Joukamaa, M., Isohanni, M., Jones, P., Jarvelin, M.R. (1998). Comorbidity of hospital treated psychiatric and physical disorders with special reference to schizophrenia: a 28 year follow-up of the 1966 northern Finland general population birth cohort. Public Health, 112, 221-228.

Manyande, A., Chayen, S., Priyakumar, P.C., Smith, C.T., Hayes, M., Higgins, D., Kee, S., Phillips, S., Salmon, P. (1992). Anxiety and endocrine response to surgery: Paradoxical effects of preoperative relaxation training. Psychosomatic Medicine, 54, 275-287.

Mason, J.W., Giller, E.L., Kosten, T.R., Yehuda, R. (1990). Psychoendocrine approaches to the diagnosis and pathogenesis of PTSD. In: E.Giller (Ed.) Biologic assessment and treatment of post-traumatic stress disorders, Washington, DC: American Psychiatric Press, 65-86.

Maquet, P., Laureys, S., Peignen, Ph., Fuchs, S., Petiau, Ch., Phillips, C., Aerts, J., Del Fiore, G., Degueldre, C., Meulemans, Th., Luxen, A., Franck, G., van der Linden, M., Smith, C., Claremans, A. ( 2000) Experience-dependent changes in cerebral activation during human REM sleep. Nature Neuroscience, 3, 831-836.

McGrath, M. J., \& Cohen, J.B. (1978). REM sleep facilitation of adaptive making behavior: A review of the literature. Psychological Bulletin, 85, 24-57.

McGuire, P.K., Silberweig, D.A., Wright, I., Murray, R.M., Frackowiak, R.S.J., \& Frith C.D. (1996). The neural correlates of inner speech and auditory verbal imagery in schizophrenia: Relationship to auditory verbal hallucination. British Journal of Psychiatry, 169, 148-159.

Mendelson, W.B., Gillin, J.C., \& Wyatt, R.J. (1977). Human sleep and its disorders. New York, London: Plenum Press. Miller, N.E. (1976). Learning, stress and psychosomatic symptoms. Acta Neurobiologiae Experimentalis, 36, 141-156. Miller, W.R., Rosellini, R.A., Seligman, M.E.P. (1977). Learned helplessness and depression. In: J.D.Maser, M.E.P. Seligman (Eds.) Psychopathology: Experimental Models. San Francisco. W.H.Freeman, 104-130.

Mirmiran, M., van den Poll, N.E., Corner, M.A., van Ogen H.G., Bour, H.L. (1981). Suppression of active sleep by chronic treatment with chlorimipramine during early postnatal development: Effect upon adult sleep and behavior in the rat. Brain Research, 204, 129-146.

Mollenhour, M.N., Voorhees, J.W., \& Davis, S.F. (1977). Sleepy and hostile: the effects of REM sleep deprivation on shock-elicited aggression. Animal Learning and Behavior, 5, 148-152. 
Montangero, J. (1993). Dream, problem solving and creativity. In: Dreaming as cognition. C.Cavallero, D. Foulkes (Eds) Harvester Wheatsheaf, 93-113.

Morrison, A.R.(1982). Central activity states: overview. In: Neural Basis of Behavior. Spectrum Publication Inc., 3-17.

Mukhametov, L. (1988). The absence of paradoxical sleep in dolphins. In: W.P.Koella, F.Obal, H.Schulz, P.L.Visser (Eds.) Sleep'86, Stuttgart, New York: Gustav Fischer Verlag, 154156.

Natelson, B. (1983). Stress, predisposition and the onset of serious disease: Implication about psychosomatic etiology. Neuroscience and Biobehavioral Reviews, 7, 511-528.

Nemeroff, Ch.B. (1998). The neurobiology of depression. Scientific American: Feature Article, June.

Newman, L.S. \& Wadas, R.F. (1997) When the stakes are higher: Self-esteem instability and self-handicapping. Journal of Social Behavior and Personality, 12, 217-233.

Neylan, Th. C., van Kammen, D.P., Kelley, M.E., \& Peters, J.L. (1992). Sleep in schizophrenic patients on and off halloperidol therapy. Clinical stable vs. relapsed patients. Archives of General Psychiatry, 49, 643-649.

Nielsen, T.A. (2000) Cognition in REM and NREM sleep: A review and possible reconciliation of two models of sleep mentation. The Behavioral and Brain Sciences, 23, 851-867.

Nofzinger, E.A., van Kammen, D.P., Gilbertson, M.W., Gurklis, J.A., \& Peters, J.L.(1993). Electroencephalographic sleep in clinically stable schizophrenic patients; Two weeks vs. six weeks neuroleptic free. Biological Psychiatry, 33, 829-835.

O'Gorman J.G., \& Jamieson R.D. (1977). Short latency acceleration of human heart rate as a function of stimulus intensity. Perceptual and Motor Skills, 45, 579-583.

Oniani, T., \& Lortkipanidze, N. (1985). Effect of paradoxical sleep deprivation on the learning and memory. In: T.N.Oniani (Ed.) Neurophysiology of Motivation, Memory and SleepWakefulness Cycle, Tbilisi, Metzniereba, 214-234.

Oniani, T.N., Lortkipanidze, N.D., Mgaloblishvili, M.M., Maisuradze, L.M., Oniani, L.T., Babilodze, M.R., \& Gvasalia M.G. (1988) Neurophysiological analysis of paradoxical sleep deprivation. In: T.N.Oniani (Ed.) Neurobiology of SleepWakefulness Cycle, Tbilisi, Metzniereba, 19-42.

Overmeier, J.B., \& Seligman, M.E.P. (1981) Effects of inescapable shock upon subsequent escape and avoidance learning. Journal of Comparative Physiological Psychology, 16, 213-229.

Pagel, I., Pegram, V., Vaughan, S., Donaldson, P., Bridge, W. (1973). The relationship of REM sleep with learning and memory in mice. Behavioral Biology, 9, 383-388.

Panksepp, J. (2000). "The dream of reason creates monsters"...especially when we neglect the role of emotions in REM-states. Behavioral and Brain Sciences, 23, 988-990.

van Dongen, P.A. (1981). The human locus coeruleus in neurology and psychiatry. Progress in Neurobiology, 17: 97-139.

Pearlman, C. (1979). REM sleep and information processing: Evidence from animal studies. Neuroscience and Biobehavioral Reviews, 3, 57-68.

Peterson, C. (2000). The future of optimism. American Psychologist, 55, 44-55.

Peterson, C., Maier S.F., \& Seligman M.E.P. (1993). Learned helplessness. A theory for the age of personal control. New York, Oxford : Oxford University Press.
Pittman N., \& Pittman T. (1979). Effects of amount of helplessness training and internal -external locus of control on mood and performance. Journal of Personality and Social Psychology, 37, 39-47.

Posner, M. I., \& Rothbart, M.K. (1998). Attention, selfregulation and consciousness. Philosophy Transactions of the Royal Society of London: Biological Sciences, 353, 19151927.

Powell, L., Shaker, L.A., Vaccarino, L.V., Thoresen, C.E., \& Patillo J.R. (1993) Psycho-social predictors of mortality in 83 women with premature acute myocardial infarction. Psychosomatic Medicine, 55, 426-433.

Procyk, E., Tanaka, Y.L., \& Joseph, J.P. (2000). Anterior cingulate activity during routine and non-routine sequential behaviors in macaques. Nature Neuroscience, 5, 502-508.

Purcell, S., Moffitt, A., \& Hoffmann, R. (1993). Waking, dreaming and self-regulation. In : A. Moffitt, M.Kramer, R. Hoffmann (Eds.) The Functions of Dreaming. New York, Albany: State University of New York Press, 197-260.

Putkonen, P.T.S. (1979). Alpha- and beta- adrenergic mechanisms in the control of sleep stages. In: R.G.Priest, A. Pletscher, J. Ward (Eds.) Sleep research. Proceedings of the Northern European Symposium on sleep research, Basel, September 26/27, 1978, 19-34.

Putkonen, P.T.S., \& Putkonen, A.R. (1971). Suppression of paradoxical sleep following hypothalamic defence reactions in cats during normal conditions and recovery from P.S. deprivation. Brain Research, 26, 334-347.

Ragland, D.R., \& Brand, R.J. (1988) Type A behavior and mortality from coronary heart disease. New England Medical Journal, 318, 65-69.

Rechtschaffen, A., Gilliland, M.A., Bergmann, B.M., \& Winter J.B. (1983). Physiological correlates of prolonged sleep deprivation in rats. Science, 221, 182-184.

Reynolds, C., Kupfer, D. (1988). Sleep in depression. In: R. Williams, I. Karacan, C. Moore (Eds.) Sleep Disorders, Diagnosis and Treatment. New York: J. Willey and Sons, 147-164. Riemann, D., Wiegand, M., Majer-Trendel, K., Dippel, B., \& Berger, M. (1988). Dream recall and dream content in depressive patients, patients with anorexia nervosa and normal controls. In: W.P.Koella, F.Obal, H. Schulz \& P. Visser (Eds.) Sleep'86, Stuttgart, Gustav Fischer Verlag, 373-375.

Rodin, J. (1986). Aging and health. Effects of the sence of control. Science, 233, 1271-1276.

Romney, D.M. (1993). Attributional style and self-esteem. Abstracts of the III European Congress of Psychology, Tampare, 370 .

Rosenbaum, D.L., \& Seligman, M.E.P. (1989). Abnormal psychology. New York: Norton.

Rosenzweig, S. (1935). A test for types of reaction to frustration. American Journal of Orthopsychiatry, 5, 395-403.

Rotenberg, V.S. (1980). Sensitivity, neuroticism and sleep disturbance: Some controversial problems. Waking and Sleeping, 4, 271-279.

Rotenberg, V.S. (1982). The adaptive function of sleep. Reasons and signs of its disturbance. (In Russian) Moscow: Nauka publisher.

Rotenberg, V.S. (1984). Search activity in the context of psychosomatic disturbances, of brain monoamines and REM sleep function. Pavlovian Journal of Biological Science, 19, $1-15$. 
Rotenberg, V.S. (1988). Functional deficiency of REM sleep and its role in the pathogenesis of neurotic and psychosomatic disturbances. Pavlovian Journal of Biological Science, 23, 13.

Rotenberg, V.S. (1992). Sleep and memory I: The influence of different sleep stages on memory. Neuroscience and Biobehavioral Reviews, 16, 497-502.

Rotenberg, V.S. (1993). Richness against freedom: Two hemisphere functions and the problem of creativity. European Journal for High Ability, 4: 11-19.

Rotenberg V.S. (1993). REM sleep and dreams as mechanisms of the recovery of search activity. In: A. Moffitt, M.Kramer \& R. Hoffmann (Eds.) The Functions of Dreaming. New York: State University of New York, 261-292.

Rotenberg, V.S. (1994). The revised monoamine hypothesis: Mechanism of antidepressant treatment in the context of behavior. Integrative Physiological and Behavioral Science, 29, 182-188.

Rotenberg, V.S. (1995). Right hemisphere insufficiency and illness in the context of search activity concept. Dynamische Psychiatrie/Dynamic Psychiatry, 150/151, 54-65.

Rotenberg, V.S. (1996). Learned helplessness and sleep: discussion of contradictions. Homeostasis in Health and Disease, 37, 89-92.

Rotenberg, V.S. (2000). Anorexia nervosa: Old contradictions and a new theoretical approach. International Journal of Psychiatry in Clinical Practice, 4, 89-92.

Rotenberg, V.S., \& Biniaurishvili, R. (1973). Psychophysiological investigation into night sleep. Zhurnal Vysshey Nervnoy Deyatelnosti, 26, 424-428.

Rotenberg V.S., \& Arshavsky V.V. (1979a). Search activity and its impact on experimental and clinical pathology. Activitas Nervosa Superiores (Praha), 21, 105-115.

Rotenberg, V.S., Arshavsky, V.V. (1979b). REM sleep, stress and search activity. Waking and Sleeping, 3, 235-244.

Rotenberg, V.S., \& Alexeyev, V. (1981). Essential hypertension: A psycho-somatic feature or a psychsomatic disease? A differential analysis of cases in terms of search activity concept. Dynamische Psychiatrie/ Dynamic Psychiatry, 68, 129139.

Rotenberg, V.S., \& Arshavsky, V.V. (1984). Search activity and adaptation. Moscow: Nauka Publisher.

Rotenberg, V.S., \& Vedenyapin, A.B. (1985). GSR as a reflection of decision-making under conditions of delay. Pavlovian Journal of Biological Science, 20, 11-14.

Rotenberg, V.S., \& Korosteleva, I.S. (1990). Psychological aspects of the search activity and learned helplessness in psychosomatic patients and healthy testees. Dynamische Psychiatrie/ Dynamic Psychiatry, 120, 1-13.

Rotenberg, V.S., \& Schattenstein, A. (1990). Neurotic and psychosomatic disorders. Interdependence in terms of the search activity concept. Pavlovian Journal of Biological Science, 25, 43-47.

Rotenberg V.S., \& Boucsein W. (1993). Adaptive versus maladaptive emotional tension. Genetic, Social and General Psychology Monographs, 119, 207-232.

Rotenberg, V.S., Kovalzon, V.M., \& Tsibulski, V.L. (1986). Paradoxical sleep: Protection from stress. Science in the USSR, 2: 45-51.

Rotenberg, V.S., Sirota, P., \& Elizur, A. (1996). Psychoneuroimmunology: Searching for the main deteriorating psycho- behavioral factor. Genetic, Social and General Psychological Monographs, 122, 331-346.

Rotenberg, V.S., Kutsay, S., \& Venger, A. (1998). Behavioral attitudes and distress in adolescents: Relationship to age and gender. Homeostasis in Health and Disease, 39, 57-64.

Rotenberg, V.S., Kutsay, S., \& Venger, A. (2001). Behavioral attitudes and the level of distress in the process of adaptation to the new society. Stress Medicine, 17, 177-183.

Rotenberg, V.S., Tobin, M., Krause, D., \& Lubovikov, I. (1996). Psychosocial problems faced during absorbtion of Russian-speaking new immigrants into Israel: A systematic approach. Israel Journal of Psychiatry and Related Sciences, $33,40-49$.

Rotenberg, V.S., Kayumov, L., Indursky, P., Hadjez, J., Kimhi, R., Sirota, P., Bichucher, A., \& Elizur A. (1997a). REM sleep in depressed patients: Different attempts to achieve adaptation. Journal of Psychosomatic Research, 42, 565-575. Rotenberg, V.S., Hadjez, J., Kimhi, R., Indurski, P., Sirota, P., Mosheva, T., Benatov, R., Elizur, A. (1997b). First night effect in depression: New data and a new approach. Biological Psychiatry, 42, 267-274.

Rotenberg, V.S., Hadjez, J., Indursky, P., Martin, T., Barak, Y., Gutman, Y., Elizur, A. (1997c). Eye movement density in positive and negative schizophrenia. Homeostasis in Health and Disease, 38, 97-102.

Rotenberg, V.S., Hadjez, J., Martin, T., Indursky, P., Michailov, N., Barak, Y., Weiss, R., Gutman, Y., Shamir, E., Elizur, A. (1998) First night effect in different forms of schizophrenia (Pilot investigation). Dynamische Psychiatrie/ Dynamic Psychiatry, 172/173, 421-430.

Rotenberg, V.S., Kayumov, L., Indursky, P., Kimhi, R., Venger, A., Melamed, Y., Elizur, A. (1999). Slow wave sleep redistribution and REM sleep eye movement density in depression: Toward the adaptive function of REM sleep. Homeostasis in Health and Disease, 39, 81-89.

Rotenberg, V.S., Indursky, P., Kayumov, L., Sirota, P., \& Melamed, Y. (2000). The relationship between subjective sleep estimation and objective sleep variables in depressed patients. International Journal of Psychophysiology, 37, 291297.

Rotenberg, V.S., Indursky, P., Kimhi, R., Hadjez, J., Gutman, Y., Shamir, E., Barak Y., \& Elizur, A. (2000). The relationship between objective sleep variables and subjective sleep estimation in schizophrenia. International Journal of Psychiatry in Clinical Practice, 4, 63-67.

Salmon, P., Pearce, S., \& Smith, C.C. (1992). The relationship of preoperative distress to endocrine and subjective response to surgery: Support for Janis theory. Journal of Behavioral Medicine, 11, 599- 613.

Scheier, M.F., Carver, C.S., Bridges, M.W. (1994). Distinguishing optimism from neuroticism (and trait anxiety, selfmastery and self-esteem). A re-evaluation of life orientation test. Journal of Personality and Social Psychology, 67, 10631078.

Schiff, B., Rusak, B., \& Block, R. (1971). The determination of reinforcing intracranial stimulation: On ecological approach. Physiology and Behavior, 7, 215-220.

Schors, R. (1970). Leistungsmotivation und Aggressionsverhalten by Hypertonikern. Hamburg.

Seligman, M.E.P. (1975). Helplessness: On depression, development and death. San Francisco: W.H. Freeman. 
Seligman, M.E.P. (1982). Learned helplessness and life-span development. Paper presented on the International Conference of Life-Course Research on Human Development. Max-Plank Institute: Berlin.

Selye, H. (1974). Stress without distress. Philadelphia, New York: J.B. Lippincott.

Siegel, J.M., \& Rogawski, M.A. (1988). A function for REM sleep: Regulation of noradrenergic receptor sensitivity. Brain Research Reviews, 13, 213-233.

Simonov P. (1975). The High Nervous Activity of the Man. Moscow: Nauka Publisher (in Russian).

Simonov P.V. (1981) The emotional brain. Moscow: "Nauka" (in Russian).

Sims, A. (1973). Mortality in neurosis. Lancet, 2, 1072-1076.

Slade, P.D. (1982). Towards a functional analysis of anorexia nervosa and bulimia nervosa. British Journal of Clinical Psychology, 21, 167-179.

Smith, C. (1985). Sleep states and learning. A review of the animal literature. Neuroscience and Biobehavioral Reviews, 9, 157-168.

Smith, C. (1993). REM sleep and learning : some recent findings. In: A. Moffitt, M.Kramer, R. Hoffmann (Eds.) The Functions of Dreaming. New York, Albany: State University of New York Press, 341-362.

Smith, C. (1995). Sleep states and memory process. Behavior and Brain Research, 69, 137-145.

Snyder, C.R. (1994). The psychology of hope. New York, London: The Free Press.

Solms, M. (2000). Dreaming and REM sleep are controlled by different brain mechanisms. The Behavioral and Brain Sciences, 23, 843-850.

Soubrie, P. (1982). Inferring anxiety and antianxiety effects in animals. The Behavioral and Brain Sciences, 5, 502-503.

Spielberger, C.D. (1962). The effects of manifest anxiety on the academic achievement of college students. Mental Hygiene, 46, 420-426.

Stern, W.C. (1971). Acquisition impairments following rapid eye movements sleep deprivation in rats. Physiology and Behavior, 7, 345-352.

Stern, W.C., \& Morgane P.I. (1974) Theoretical view of REM sleep function: Maintenance of catecholamine systems in the central nervous system. Behavioral Biology, 11, 1-32.

Stickgold, R. (1998). Sleep: off-line memory reprocessing. Trends in Cognitive Sciences, 2, 484-492.

Swerdlow N.R., \& Koob G.K. (1987). Dopamine, schizophrenia and depression. Toward a unified hypothesis of coticostriato-pallido-thalamic function. The Behavioral and Brain Science 10, 197-245.

Taylor, Sh.E., \& Brown, J.D. (1994). Illusions and well being revisited: separating fact from fiction. Psychological Bulletin 116, 21-27.

Tice, D.M. (1991). Esteem protection or enhancement? Selfhandicapping motives and attributions differ by trait selfesteem. Journal of Personal and Social Psychology, 60, 711725.

Tiller, J., Schmidt, U., Ali, S., \& Treasure, J. (1995). Patterns of punitiveness in women with eating disorders. International Journal of Eating Disorders 17, 365-371.

Toro, J., Nicolau, R., \& Cervera, M. (1995). A clinical and phenomenological study of 185 Spanish adolescents with anorexia nervosa. European Child and Adolescents Psychiatry, 4, 165-174.

Troop, N.A., \& Treasure, J.L. (1997). Setting the scene for eating disorders II. Children helplessness and mastery. Psychological Medicine 27: 531-538.

Uexkull, T. (1979). Lehrbuch der Psychosomatischen Krankheiten. Baltimore: Urban \& Schwarzenberg.

Valdman, A.V., Kozlovskaya, M.M., Medvedev, O.S. (1979). Regulation of emotional stress by pharmacological agents (in Russian). Moscow: Medicina Publisher.

Venger, A., Rotenberg, V.S., \& Desiatnokov, Y. (1996). Evaluation of search activity and other behavioral attitudes in indefinite situations. Dynamische Psychiatrie/Dynamic Psychiatry, 160/161, 368-377.

Vogel, G.W. (2000). Critique of current dream theories. Behavioral and Brain Sciences, 23, 1014-1016.

Vogel, G.M., Vogel, F., McAbce, R.S., \& Thurmoud, A.J. (1980). Improvement of depression by REM sleep deprivation: New findings and a theory. Archives of General Psychiatry 37, 247-253.

Waller G., \& Hodgson S. (1996). Body image distortion in anorexia and bulimia nervosa. The role of perceived and actual control. Journal of Nervous and Mental Diseases, 184, 213-219.

Wauquier, A. (1980). The pharmacology of catecholamine involvement in the neural mechanisms of reward. Acta Neurobiologiae Experimentalis, 40, 665-686.

Weinberg, I.(2000) The ultimate resignation: suicide and search activity. Neuroscience and Biobehavioral Reviews. 24, 605-626.

Weiss, J. (1977). Psychological and behavioral influences on gastrointestinal lesions in animal models. In: J.Maser, M.Seligman (Eds.) Psychopathology: Experimental Models. San Francisco, W.H. Freeman, 232-269.

Wiederman, M.W., Pryor, T., \& Morgan, C.D. (1996). The sexual experience of women diagnosed with anorexia nervosa or bulimia nervosa. International Journal of Eating Disorders 19, 109-118.

Wilder, J. (1931) Das "Ausgangswert-Gesetz" - ein unbeachtetes biologische Gesetz: seine Bedeutung fur Forschung und Praxis. Klinische Wissenschaft, 41, 1889-1893.

Williams, R.B. (1986). Beyond Type A: Psychological and physiological refinements. Paper, presented at the annual meeting of the American Psychological Association. Washington, DC

Wolkin, A., Sanfilipo, M., Duncan, E., Angrist, B., Wolf, A.P., Cooper, T., Brodie, J.D., Laske, E., Rotrosen, J.P. (1996). Blunted change in cerebral glucose utilization after haloperidol treatment in schizophrenic patients with prominent negative symptoms. American Journal of Psychiatry, 153, 346-354.

Yehuda, R., Resnick, H., Kahana, B., \& Giller, E.L. (1993). Long-lasting hormonal alterations to extreme stress in humans: normative or maladaptive? Psychosomatic Medicine, 55, 287-297.

Yerkes, R.M., \& Dodson, J.D. (1908). The relation of strength of stimulus to rapidity of habit formation. Journal of Comparative and Neurological Psychology, 18, 459-482.

Zuckerman, M. (1984). Sensation seeking: A comparative approach to human traits. The Behavioral and Brain Science, 7, 413-434. 